\title{
Isobaric Vapor-Liquid Equilibrium Data and Excess Properties of Binary Systems Comprised of Alkyl Methanoates + Hexane
}

\author{
Juan Ortega,* Gisela Sabater, Ignacio de la Nuez, and Juan J. Quintana \\ Laboratorio de Termodinámica y Fisicoquímica de Fluidos, Parque Científico-Tecnológico, Universidad de Las Palmas \\ de Gran Canaria, 35071-Las Palmas de Gran Canaria, Canary Islands, Spain
}

\section{Jaime Wisniak}

Department of Chemical Engineering, Ben-Gurion University of the Negev, Beer-Sheva 84105, Israel

\begin{abstract}
In this work, we report the experimental values of the excess quantities $H_{\mathrm{m}}^{\mathrm{E}}$ and $V_{\mathrm{m}}^{\mathrm{E}}$ and the isobaric equilibrium data (VLE) at $101.32 \mathrm{kPa}$ for the four mixtures of alkyl methanoates (methyl to butyl) and hexane. The results indicate that for these four mixtures $\left(\partial H_{\mathrm{m}}^{\mathrm{E}} / \partial T\right)_{p}>0$ and $\left(\partial V_{\mathrm{m}}^{\mathrm{E}} / \partial T\right)_{p}>0$. VLE data were found to be thermodynamically consistent with the Fredenslund method. All the binary mixtures presented here, except for the system (butyl methanoate + hexane), present a minimum-boiling temperature azeotrope with coordinates $\left(x_{\mathrm{az}}, T_{\mathrm{az}} / \mathrm{K}\right),(0.832,302.62)$ for (methyl methanoate + hexane $),(0.703,323.32)$ for (ethyl methanoate + hexane $)$, and $(0.283,339.10)$ for (propyl methanoate + hexane). Simultaneous correlations performed with the VLE data and excess enthalpies using a simple polynomial model, with temperature-dependent coefficients, produced acceptable estimations. Application of the UNIFAC model in the versions of Hansen et al. (Ind. Eng. Chem. Res. 1991, 30, 2355-2358) and Gmehling et al. (Ind. Eng. Chem. Res. 1993, 32,178-193) produced similar predictions for all four systems, of which only the ones for the methyl methanoate + hexane mixture are acceptable. Differences increase steadily with increasing methanoate chain length. Estimation of enthalpies with the second of the versions indicated, however, produced mean errors of $10 \%$, which could be considered as acceptable.
\end{abstract}

\section{Introduction}

For several years, our research group has been studying the thermodynamic properties of mixtures containing alkyl esters. In the field of vapor-liquid equilibria (VLE), a considerable amount of work has been conducted on binary systems of esters + alkanols, providing an important experimental contribution to these systems and specifically to mixtures containing alkyl

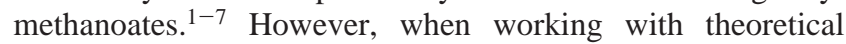
modeling based on group contribution methods, the predictions were found to be unacceptable, revealing in some cases large discrepancies. A literature review shows only few studies of VLE of mixtures of alkyl methanoates + alkanes mixtures. . $^{1,3,4,8}$ These binary systems are considered as a preliminary work since they have helped to establish the behavior of methanoates in solution with inert substances such as alkanes as well as providing interesting information about the $\mathrm{CH}_{2} / \mathrm{HCOO}$ interaction. We have published data on the excess enthalpies $H_{\mathrm{m}}^{\mathrm{E}}$ and volumes $V_{\mathrm{m}}^{\mathrm{E}}$ at $298.15 \mathrm{~K}$ for binary systems composed of (alkyl methanoates + alkanes), ${ }^{3,4,9-12}$ which will also be used in this study. Also, VLE data of the binary system (ethyl methanoate + hexane) were measured at $101.32 \mathrm{kPa}$ and published in a previous paper. ${ }^{3}$ VLE data ${ }^{8}$ at $101.32 \mathrm{kPa}$ and $\mathrm{LLE}^{13}$ at $19 \mathrm{kPa}$ have been reported for the system (methyl methanoate + hexane) along with values of $H_{\mathrm{m}}^{\mathrm{E}}$ at $T=$ $298.15 \mathrm{~K}$ for the system (ethyl methanoate +hexane). ${ }^{14}$

In this first work of the series in which hexane is the common substance, a series of studies will be carried out systematically on mixtures of alkyl methanoates (methyl to butyl) with different

\footnotetext{
* Corresponding author. E-mail: jortega@dip.ulpgc.es.
}

alkanes. In this way, we will help to expand the existing database, obtaining more information about the behavior of these substances. Moreover, modeling of primary systems (methanoates + alkanes) will help us to define the $\mathrm{CH}_{2} / \mathrm{HCOO}$ interaction, which will improve predictions of other systems that involve the G/HCOO interaction of methanoates with another functional group G. In this sense, this project on methanoates will include extensive experimental information with data of VLE, $H_{\mathrm{m}}^{\mathrm{E}}$, and $V_{\mathrm{m}}^{\mathrm{E}}$ measured at different temperatures. Since data for $H_{\mathrm{m}}^{\mathrm{E}}$ and $V_{\mathrm{m}}^{\mathrm{E}}$ at $298.15 \mathrm{~K}$ have already been presented in previous works, ${ }^{1-14}$ we decided to provide experimental data for these excess properties at other temperatures.

Another important aspect of this series of works is to verify the suitability of a new procedure to treat VLE data and to study the predictive capacity of the UNIFAC group contribution method using the original version with the parameters of Hansen et al. ${ }^{15}$ and the newer version of Gmehling et al., ${ }^{16}$ which can be used to estimate properties different from VLE using the same set of interaction parameters.

\section{Experimental Section}

Materials. Alkyl methanoates and alkanes used in the experimental part of this work are of the highest commercial purity and were supplied by Aldrich. Nonetheless, before their use, all the products were subjected to a preliminary treatment that consisted of degassifying by ultrasound for a sufficient length of time, followed by moisture reduction using a $0.3 \mathrm{~nm}$ Fluka molecular sieve. The quality of the products was verified with a GC model HP6890 and found to be similar to that indicated by the manufacturer. The purity of the products used 
Table 1. Physical Properties of Pure Compounds

\begin{tabular}{|c|c|c|c|c|c|c|c|c|c|c|c|c|}
\hline \multirow[b]{2}{*}{ compound } & \multirow[b]{2}{*}{ mass fraction } & \multicolumn{2}{|c|}{$T_{\mathrm{b}, \mathrm{i}}^{\circ}$} & \multirow{2}{*}{$\begin{array}{c}T \\
\mathrm{~K}\end{array}$} & \multicolumn{2}{|c|}{$\rho / \mathrm{kg}^{\prime} \cdot \mathrm{m}^{-3}$} & \multicolumn{2}{|c|}{$10^{3} \bar{\alpha} / \mathrm{K}^{-1}$} & \multicolumn{2}{|c|}{$n_{\mathrm{D}}$} & \multicolumn{2}{|c|}{$10^{4} b$} \\
\hline & & $\exp$ & lit & & $\exp$ & lit & $\exp$ & lit & $\exp$ & lit & $\exp$ & lit \\
\hline $\mathrm{HCOOCH}_{3}$ & $>0.99$ & 304.70 & $\begin{array}{l}304.90^{a} \\
304.79^{b}\end{array}$ & $291.15 \rightarrow$ & 976.90 & $977.25^{c}$ & 1.46 & $1.56^{g}$ & 1.3452 & & & \\
\hline & & & & $298.15 \rightarrow$ & 966.54 & $\begin{array}{l}966.40^{a} \\
966.18^{b}\end{array}$ & & & 1.3415 & $\begin{array}{l}1.3415^{a} \\
1.3412^{b}\end{array}$ & 5 & $4^{a}$ \\
\hline $\mathrm{HCOOCH}_{2} \mathrm{CH}_{3}$ & $>0.97$ & 327.33 & $327.46^{a}$ & $\begin{array}{l}291.15 \rightarrow \\
298.15 \rightarrow \\
318.15 \rightarrow\end{array}$ & $\begin{array}{l}924.70 \\
915.16 \\
888.42\end{array}$ & $\begin{array}{l}924.59^{c} \\
915.30^{a} \\
888.19^{d}\end{array}$ & 1.48 & $1.42^{g}$ & $\begin{array}{l}1.3614 \\
1.3580 \\
1.3474\end{array}$ & $\begin{array}{l}1.3575^{a} \\
1.3475^{d}\end{array}$ & 5 & $5^{a}$ \\
\hline $\mathrm{HCOO}\left(\mathrm{CH}_{2}\right)_{2} \mathrm{CH}_{3}$ & $>0.97$ & 353.92 & $353.97^{a}$ & $\begin{array}{l}291.15 \rightarrow \\
298.15 \rightarrow \\
318.15 \rightarrow\end{array}$ & $\begin{array}{l}907.80 \\
899.08 \\
875.32\end{array}$ & $\begin{array}{l}907.70^{c} \\
899.60^{a} \\
875.56^{e}\end{array}$ & 1.33 & $1.28^{g}$ & $\begin{array}{l}1.3778 \\
1.3750 \\
1.3650\end{array}$ & $\begin{array}{l}1.3750^{a} \\
1.3650^{e}\end{array}$ & 5 & $5^{a}$ \\
\hline $\mathrm{HCOO}\left(\mathrm{CH}_{2}\right)_{3} \mathrm{CH}_{3}$ & $>0.97$ & 380.13 & $379.25^{a}$ & $\begin{array}{l}291.15 \rightarrow \\
298.15 \rightarrow \\
318.15 \rightarrow\end{array}$ & $\begin{array}{l}896.00 \\
888.66 \\
867.21\end{array}$ & $\begin{array}{l}893.75^{c} \\
886.90^{a} \\
867.74^{f}\end{array}$ & 1.21 & & $\begin{array}{l}1.3904 \\
1.3872 \\
1.3776\end{array}$ & $\begin{array}{l}1.3874^{a} \\
1.3773^{f}\end{array}$ & 5 & $4^{a}$ \\
\hline $\mathrm{CH}_{3}\left(\mathrm{CH}_{2}\right)_{4} \mathrm{CH}_{3}$ & $>0.99$ & 341.76 & $341.89^{a}$ & $\begin{array}{l}291.15 \rightarrow \\
298.15 \rightarrow \\
318.15 \rightarrow\end{array}$ & $\begin{array}{l}661.20 \\
654.89 \\
636.43\end{array}$ & $\begin{array}{l}660.92^{c} \\
654.84^{a} \\
636.39^{d}\end{array}$ & 1.41 & $1.39^{g}$ & $\begin{array}{l}1.3765 \\
1.3720 \\
1.3618\end{array}$ & $\begin{array}{l}1.3722^{a} \\
1.3614^{d}\end{array}$ & 5 & $5^{a}$ \\
\hline
\end{tabular}

${ }^{a}$ Ref 17. ${ }^{b}$ Ref $4 .{ }^{c}$ Values interpolated from ref 19. ${ }^{d} \operatorname{Ref} 3 .{ }^{e} \operatorname{Ref} 7 .{ }^{f} \operatorname{Ref} 6 .{ }^{g} \operatorname{Ref} 18 . \bar{\alpha}$, average expansion coefficient; $b$, slope of $n_{\mathrm{D}}=a+b T$.

Table 2. Densities $\rho$ and Excess Molar Volumes $V_{\mathrm{m}}^{\mathrm{E}}$ for Binary Systems of Alkyl Methanoate (1) + Hexane (2) at Three Different Temperatures

\begin{tabular}{|c|c|c|c|c|c|c|c|c|c|c|c|c|c|c|}
\hline$x_{1}$ & $\frac{\rho}{\mathrm{kg} \cdot \mathrm{m}^{-3}}$ & $\frac{10^{9} V_{\mathrm{m}}^{\mathrm{E}}}{\mathrm{m}^{3} \cdot \mathrm{mol}^{-1}}$ & $x_{1}$ & $\frac{\rho}{\mathrm{kg} \cdot \mathrm{m}^{-3}}$ & $\frac{10^{9} V_{\mathrm{m}}^{\mathrm{E}}}{\mathrm{m}^{3} \cdot \mathrm{mol}^{-1}}$ & $x_{1}$ & $\frac{\rho}{\mathrm{kg} \cdot \mathrm{m}^{-3}}$ & $\frac{10^{9} V_{\mathrm{m}}^{\mathrm{E}}}{\mathrm{m}^{3} \cdot \mathrm{mol}^{-1}}$ & $x_{1}$ & $\frac{\rho}{\mathrm{kg} \cdot \mathrm{m}^{-3}}$ & $\frac{10^{9} V_{\mathrm{m}}^{\mathrm{E}}}{\mathrm{m}^{3} \cdot \mathrm{mol}^{-1}}$ & $x_{1}$ & $\frac{\rho}{\mathrm{kg} \cdot \mathrm{m}^{-3}}$ & $\frac{10^{9} V_{\mathrm{m}}^{\mathrm{E}}}{\mathrm{m}^{3} \cdot \mathrm{mol}^{-1}}$ \\
\hline \multicolumn{15}{|c|}{$T=291.15 \mathrm{~K}$} \\
\hline \multicolumn{15}{|c|}{ Methyl Methanoate (1) + Hexane (2) } \\
\hline 0.0000 & 661.20 & 0 & 0.1013 & 672.60 & 804 & 0.3828 & 718.90 & 1885 & 0.6987 & 810.10 & 1435 & 0.9030 & 908.40 & 501 \\
\hline 0.0190 & 663.00 & 200 & 0.1209 & 675.30 & 894 & 0.4841 & 742.30 & 1926 & 0.7445 & 829.10 & 1212 & 0.9539 & 939.90 & 267 \\
\hline 0.0499 & 666.30 & 470 & 0.2033 & 687.10 & 1301 & 0.5462 & 759.10 & 1857 & 0.7956 & 851.50 & 1034 & 1.0000 & 976.90 & 0 \\
\hline 0.0863 & 670.60 & 730 & 0.2986 & 702.60 & 1700 & 0.6061 & 777.40 & 1725 & 0.8392 & 872.60 & 861 & & & \\
\hline \multicolumn{15}{|c|}{ Ethyl Methanoate (1) + Hexane (2) } \\
\hline 0.0000 & 661.20 & 0 & 0.2049 & 692.10 & 890 & 0.5016 & 753.0 & 1244 & 0.8029 & 842.40 & 757 & 0.9522 & 901.90 & 267 \\
\hline 0.0495 & 667.80 & 300 & 0.2531 & 700.40 & 1044 & 0.6039 & 780.00 & 1114 & 0.8259 & 860.90 & 616 & 0.9580 & 905.00 & 197 \\
\hline 0.1025 & 675.40 & 571 & 0.3068 & 710.60 & 1124 & 0.6996 & 808.20 & 956 & 0.9016 & 880.30 & 450 & 1.0000 & 924.70 & 0 \\
\hline 0.1497 & 682.80 & 744 & 0.3937 & 728.20 & 1241 & 0.7504 & 824.60 & 851 & 0.9065 & 882.40 & 425 & & & \\
\hline \multicolumn{15}{|c|}{ Propyl Methanoate (1) + Hexane (2) } \\
\hline 0.0000 & 661.20 & 0 & 0.2001 & 696.50 & 610 & 0.5017 & 761.80 & 756 & 0.8013 & 842.80 & 417 & 1.0000 & 907.80 & 0 \\
\hline 0.0544 & 670.10 & 237 & 0.2480 & 705.80 & 694 & 0.6122 & 789.60 & 676 & 0.8499 & 857.80 & 326 & & & \\
\hline 0.0893 & 676.00 & 374 & 0.2521 & 706.60 & 703 & 0.6985 & 813.10 & 556 & 0.9057 & 875.50 & 234 & & & \\
\hline 0.1509 & 687.40 & 477 & 0.3979 & 737.60 & 782 & 0.7473 & 827.00 & 483 & 0.9568 & 892.90 & 88 & & & \\
\hline \multicolumn{15}{|c|}{ Butyl Methanoate (1) + Hexane (2) } \\
\hline 0.0000 & 661.20 & 0 & 0.1928 & 699.50 & 414 & 0.5021 & 768.30 & 466 & 0.8020 & 842.70 & 226 & 1.0000 & 896.00 & 0 \\
\hline 0.0445 & 669.60 & 152 & 0.2490 & 711.40 & 459 & 0.5957 & 790.70 & 412 & 0.8532 & 856.10 & 179 & & & \\
\hline 0.0900 & 678.60 & 247 & 0.3018 & 722.70 & 504 & 0.6963 & 815.70 & 318 & 0.8987 & 868.20 & 132 & & & \\
\hline 0.1461 & 689.80 & 364 & 0.4025 & 745.20 & 505 & 0.7541 & 830.40 & 262 & 0.9575 & 884.30 & 46 & & & \\
\hline \multicolumn{15}{|c|}{$T=298.15 \mathrm{~K}$} \\
\hline \multicolumn{15}{|c|}{ Methyl Methanoate (1) + Hexane (2) } \\
\hline 0.0000 & 654.89 & 0 & 0.1642 & 674.80 & 1156 & 0.4987 & 740.05 & 1886 & 0.7972 & 845.31 & 1089 & 1.0000 & 966.54 & 0 \\
\hline 0.0376 & 659.63 & 165 & 0.2352 & 685.32 & 1519 & 0.5979 & 768.90 & 1700 & 0.8497 & 871.94 & 805 & & & \\
\hline 0.0816 & 664.26 & 591 & 0.2936 & 695.29 & 1708 & 0.7062 & 806.50 & 1436 & 0.9050 & 902.05 & 595 & & & \\
\hline 0.1327 & 670.55 & 964 & 0.3903 & 714.41 & 1867 & 0.7433 & 821.74 & 1278 & 0.9582 & 936.28 & 273 & & & \\
\hline \multicolumn{15}{|c|}{ Ethyl Methanoate (1) + Hexane (2) } \\
\hline 0.0000 & 654.89 & 0 & 0.1715 & 679.95 & 776 & 0.4765 & 739.84 & 1214 & 0.6441 & 783.83 & 1012 & 0.8840 & 865.42 & 373 \\
\hline 0.0777 & 665.63 & 394 & 0.2501 & 693.44 & 976 & 0.5354 & 754.13 & 1192 & 0.6993 & 800.39 & 904 & 0.9643 & 898.98 & 104 \\
\hline 0.1291 & 673.25 & 622 & 0.3270 & 707.73 & 1135 & 0.5955 & 769.95 & 1118 & 0.7956 & 832.38 & 647 & 1.0000 & 915.16 & \\
\hline \multicolumn{15}{|c|}{ 0Propyl Methanoate (1) + Hexane (2) } \\
\hline 0.0000 & 654.89 & 0 & 0.2941 & 709.36 & 705 & 0.5453 & 765.36 & 783 & 0.7650 & 824.15 & 509 & 0.9567 & 884.05 & 123 \\
\hline 0.0787 & 668.91 & 284 & 0.3597 & 722.93 & 778 & 0.6019 & 779.74 & 713 & 0.8120 & 838.34 & 385 & 1.0000 & 899.08 & 0 \\
\hline 0.1478 & 681.52 & 399 & 0.4297 & 738.37 & 784 & 0.6599 & 794.74 & 675 & 0.8656 & 854.66 & 297 & & & \\
\hline 0.2237 & 695.63 & 573 & 0.4878 & 751.68 & 789 & 0.7154 & 810.00 & 590 & 0.9210 & 872.18 & 206 & & & \\
\hline \multicolumn{15}{|c|}{ Butyl Methanoate (1) + Hexane (2) } \\
\hline 0.0000 & 654.89 & 0 & 0.2658 & 708.76 & 391 & 0.5876 & 781.81 & 361 & 0.8574 & 849.77 & 113 & 1.0000 & 888.66 & 0 \\
\hline 0.0729 & 669.39 & 106 & 0.3360 & 723.94 & 423 & 0.6855 & 805.81 & 277 & 0.8986 & 860.63 & 76 & & & \\
\hline 0.1321 & 681.03 & 243 & 0.3698 & 731.40 & 429 & 0.7677 & 826.55 & 200 & 0.9227 & 867.09 & 47 & & & \\
\hline 0.1967 & 694.20 & 335 & 0.4886 & 758.31 & 428 & 0.8136 & 838.26 & 167 & 0.9714 & 880.08 & 18 & & & \\
\hline \multicolumn{15}{|c|}{$T=308.15 \mathrm{~K}$} \\
\hline \multicolumn{15}{|c|}{ Ethyl Methanoate (1) + Hexane (2) } \\
\hline 0.0000 & 646.07 & 0 & 0.1539 & 667.20 & 810 & 0.4915 & 731.90 & 1395 & 0.7971 & 819.90 & 810 & 1.0000 & 902.07 & 0 \\
\hline 0.0485 & 651.90 & 320 & 0.2548 & 683.80 & 1137 & 0.5935 & 757.80 & 1255 & 0.9063 & 860.70 & 458 & & & \\
\hline 0.1103 & 660.50 & 654 & 0.3998 & 711.60 & 1372 & 0.6998 & 788.00 & 1086 & 0.9488 & 878.70 & 264 & & & \\
\hline
\end{tabular}


Table 2 (Continued)

\begin{tabular}{|c|c|c|c|c|c|c|c|c|c|c|c|c|c|c|}
\hline$x_{1}$ & $\frac{\rho}{\mathrm{kg} \cdot \mathrm{m}^{-3}}$ & $\frac{10^{9} V_{\mathrm{m}}^{\mathrm{E}}}{\mathrm{m}^{3} \cdot \mathrm{mol}^{-1}}$ & $x_{1}$ & $\frac{\rho}{\mathrm{kg} \cdot \mathrm{m}^{-3}}$ & $\frac{10^{9} V_{\mathrm{m}}^{\mathrm{E}}}{\mathrm{m}^{3} \cdot \mathrm{mol}^{-1}}$ & $x_{1}$ & $\frac{\rho}{\mathrm{kg} \cdot \mathrm{m}^{-3}}$ & $\frac{10^{9} V_{\mathrm{m}}^{\mathrm{E}}}{\mathrm{m}^{3} \cdot \mathrm{mol}^{-1}}$ & $x_{1}$ & $\frac{\rho}{\mathrm{kg} \cdot \mathrm{m}^{-3}}$ & $\frac{10^{9} V_{\mathrm{m}}^{\mathrm{E}}}{\mathrm{m}^{3} \cdot \mathrm{mol}^{-1}}$ & $x_{1}$ & $\frac{\rho}{\mathrm{kg} \cdot \mathrm{m}^{-3}}$ & $\frac{10^{9} V_{\mathrm{m}}^{\mathrm{E}}}{\mathrm{m}^{3} \cdot \mathrm{mol}^{-1}}$ \\
\hline \multicolumn{15}{|c|}{$T=308.15 \mathrm{~K}$} \\
\hline \multicolumn{15}{|c|}{ Propyl Methanoate (1) + Hexane (2) } \\
\hline 0.0000 & 646.07 & 0 & 0.1993 & 680.76 & 585 & 0.5069 & 745.56 & 848 & 0.8034 & 824.55 & 484 & 1.0000 & 888.36 & 0 \\
\hline 0.0693 & 657.50 & 254 & 0.3036 & 701.12 & 747 & 0.5902 & 765.82 & 817 & 0.9002 & 854.72 & 260 & & & \\
\hline 0.1125 & 665.10 & 358 & 0.3975 & 720.81 & 827 & 0.7035 & 795.66 & 687 & 0.9482 & 870.44 & 149 & & & \\
\hline \multicolumn{15}{|c|}{ Butyl Methanoate (1) + Hexane (2) } \\
\hline 0.0000 & 646.07 & 0 & 0.2005 & 685.20 & 420 & 0.5098 & 753.10 & 526 & 0.8073 & 826.30 & 285 & 1.0000 & 878.24 & 0 \\
\hline 0.0470 & 654.60 & 138 & 0.2579 & 697.20 & 473 & 0.6081 & 776.40 & 474 & 0.8511 & 837.70 & 242 & & & \\
\hline 0.1095 & 666.70 & 296 & 0.2981 & 705.70 & 513 & 0.7112 & 801.80 & 388 & 0.9081 & 852.90 & 166 & & & \\
\hline 0.1485 & 674.60 & 347 & 0.4033 & 728.80 & 540 & 0.7576 & 813.50 & 344 & 0.9598 & 867.30 & 46 & & & \\
\hline \multicolumn{15}{|c|}{$T=318.15 \mathrm{~K}$} \\
\hline \multicolumn{15}{|c|}{ Ethyl Methanoate (1) + Hexane (2) } \\
\hline 0.0000 & 636.43 & 0 & 0.1471 & 655.88 & 904 & 0.5293 & 729.70 & 1440 & 0.7932 & 805.56 & 919 & & & \\
\hline 0.0476 & 642.18 & 346 & 0.2199 & 667.46 & 1139 & 0.5869 & 744.10 & 1385 & 0.8873 & 840.19 & 541 & & & \\
\hline 0.0875 & 647.84 & 511 & 0.3041 & 681.93 & 1374 & 0.6984 & 775.52 & 1146 & 0.9692 & 874.21 & 174 & & & \\
\hline 0.1044 & 649.54 & 733 & 0.4061 & 701.97 & 1470 & 0.7476 & 790.78 & 1018 & 1.0000 & 888.42 & 0 & & & \\
\hline \multicolumn{15}{|c|}{ Propyl Methanoate (1) + Hexane (2) } \\
\hline 0.0000 & 636.43 & 0 & 0.2909 & 687.08 & 908 & 0.5747 & 750.24 & 889 & 0.7661 & 801.18 & 612 & 0.9581 & 860.97 & 126 \\
\hline 0.0796 & 648.93 & 351 & 0.3611 & 701.46 & 957 & 0.6031 & 757.34 & 859 & 0.8123 & 814.59 & 527 & 1.0000 & 875.32 & 0 \\
\hline 0.1547 & 661.76 & 602 & 0.4273 & 715.75 & 966 & 0.6617 & 772.47 & 785 & 0.8602 & 829.22 & 406 & & & \\
\hline 0.2278 & 674.93 & 805 & 0.4870 & 729.26 & 949 & 0.7118 & 785.91 & 716 & 0.9109 & 845.53 & 241 & & & \\
\hline \multicolumn{15}{|c|}{ Butyl Methanoate (1) + Hexane (2) } \\
\hline 0.0000 & 636.43 & 0 & 0.1589 & 666.90 & 417 & 0.4015 & 718.00 & 620 & 0.7460 & 799.70 & 394 & 1.0000 & 867.21 & 0 \\
\hline 0.0493 & 645.60 & 166 & 0.1975 & 674.70 & 475 & 0.4950 & 739.20 & 590 & 0.8134 & 817.05 & 296 & & & \\
\hline 0.0857 & 652.70 & 229 & 0.2452 & 684.50 & 530 & 0.5929 & 762.20 & 525 & 0.9067 & 841.50 & 182 & & & \\
\hline 0.1192 & 659.10 & 332 & 0.3006 & 696.20 & 567 & 0.7050 & 789.50 & 428 & 0.9647 & 857.10 & 110 & & & \\
\hline
\end{tabular}

was also verified by measuring the relevant physical properties such as the boiling point $T_{\mathrm{b}, i}^{\circ}$, density $\rho$, and refraction index $n_{\mathrm{D}}$ at temperatures of (298.15 and 318.15) K, except for the mixture with methyl methanoate. Since the latter has a normal boiling point $T_{\mathrm{b}, i}^{\circ}<318.15 \mathrm{~K}$, measurements were only obtained at $298.15 \mathrm{~K}$. The experimental results obtained directly are shown in Table 1 and compared with data from the literature, showing acceptable discrepancies. Other parameters obtained indirectly are also presented and compared with those in the literature when they exist.

Apparatus and Procedures. The isobaric experimental VLE was measured in a small volume device described in previous papers. ${ }^{1,3}$ It consists of a small glass ebulliometer of about $60 \mathrm{~cm}^{3}$ capacity, operating continuously with phases recirculation. Pressure was controlled using a controller/calibrator, model PPC2, supplied by Desgranges et Huot, capable of maintaining a pressure at $(101.32 \pm 0.02) \mathrm{kPa}$ during the entire measuring process. The temperature of both phases in equilibrium was measured with a digital thermometer from Comarks Electronics Ltd., model 6800, calibrated regularly according to ITS-90 and presenting an uncertainty of around $\pm 20 \mathrm{mK}$.

The concentrations of the two phases were determined with an Anton Paar densimeter, model DMA-55, with an uncertainty of $\pm 0.02 \mathrm{~kg} \cdot \mathrm{m}^{-3}$. Samples of both phases were taken after the equipment reached a stationary state with constant pressure and temperature. The methanoate concentrations $x$ and $y$ were calculated from density concentration curves $\rho=\rho(x)$ previously determined for each mixture with synthetic samples of known composition at a temperature of $T=(298.15 \pm 0.01) \mathrm{K}$, using an equation of the form $\rho\left(x_{1}\right)=\left[\left(\rho_{1}-\rho_{2}\right) x_{1}+\rho_{2}\right]-\left[x_{1}(1-\right.$ $\left.\left.x_{1}\right)\left(a x_{1}^{2}+b x_{1}+c\right)\right]$, where $\rho, \rho_{1}$, and $\rho_{2}$ are respectively the densities of the mixtures, the ester, and hexane. The concentrations of the liquid and vapor phases thus obtained present an uncertainty of \pm 0.002 units. The measurements $\left(x_{1}, \rho\right)$ for each of the studied mixtures over the entire range of concentrations allowed for calculating the values of the excess volumes $V_{\mathrm{m}}^{\mathrm{E}}$ with an uncertainty of $\pm 2 \cdot 10^{9} \mathrm{~m}^{3} \cdot \mathrm{mol}^{-1}$, while the concentrations of the synthetic samples $x_{1}$ presented an uncertainty of \pm $3 \cdot 10^{-4}$.

The excess enthalpies were determined at (291.15 and 318.15) $\mathrm{K}$ for the samples considered here, except for the system methyl methanoate + hexane, using a Calvet microcalorimeter, model MS80, by Setaram. The uncertainty of experimental results with this instrument was lower than $\pm 0.3 \mathrm{~J} \cdot \mathrm{mol}^{-1}$ for $H_{\mathrm{m}}^{\mathrm{E}}$. This estimation was made previously comparing the measurements obtained for the ethanol + nonane system and those from literature. $^{20}$ The concentrations of each point presented an uncertainty of $\pm 5 \cdot 10^{-4}$.

\section{Results}

Excess Properties. Table 2 shows the experimental data $\left(x_{1}\right.$, $V_{\mathrm{m}}^{\mathrm{E}}$ ) obtained for the binary mixtures of alkyl methanoates (ethyl to butyl) (1) + hexane (2) at $(291.15,298.15,308.15$, and 318.15$) \mathrm{K}$. For the mixture methyl methanoate + hexane, measurements were only made at (291.15 and 298.15) K, since the normal boiling temperature of methyl methanoate is $T_{\mathrm{b}, i}^{\circ}=$ $304.7 \mathrm{~K}$. The same argument applies for the measurements of $H_{\mathrm{m}}^{\mathrm{E}}$, determined at temperatures of (291.15 and 318.15) $\mathrm{K}$ for mixtures of hexane with the other three methanoates (ethyl to butyl). The pertinent values are shown in Table 3 . The $V_{\mathrm{m}}^{\mathrm{E}}$ and $H_{\mathrm{m}}^{\mathrm{E}}$ data were correlated with the molar fraction of methanoate using the following polynomial equation, which when applied to values of a generic function $Y_{\mathrm{m}}^{\mathrm{E}}$ as a function of concentration, has the form:

$$
Y_{\mathrm{m}}^{\mathrm{E}}=z_{1} z_{2} \sum_{i=0}^{2} a_{i} z_{1}{ }^{i}=z_{1}\left(1-z_{1}\right)\left(a_{0}+a_{1} z_{1}+a_{2} z_{1}{ }^{2}\right)
$$

where $z_{1}=x_{1} /\left(x_{1}+k x_{2}\right)$ is the active fraction of the compound in the binary mixture. In other words, $z_{1}$ corresponds to the 
Table 3. Excess Molar Enthalpies $H_{\mathrm{m}}^{\mathrm{E}}$ for Binary Systems of Alkyl Methanoate (1) + Hexane (2) at Two Different Temperatures

\begin{tabular}{|c|c|c|c|c|c|}
\hline$x_{1}$ & $\frac{H_{\mathrm{m}}^{\mathrm{E}}}{\mathrm{J} \cdot \mathrm{mol}^{-1}}$ & $x_{1}$ & $\frac{H_{\mathrm{m}}^{\mathrm{E}}}{\mathrm{J} \cdot \mathrm{mol}^{-1}}$ & $x_{1}$ & $\frac{H_{\mathrm{m}}^{\mathrm{E}}}{\mathrm{J} \cdot \mathrm{mol}^{-1}}$ \\
\hline \multicolumn{6}{|c|}{$T=291.15 \mathrm{~K}$} \\
\hline $\begin{array}{l}0.1408 \\
0.2520 \\
0.3379 \\
0.4008 \\
0.4618 \\
0.5094\end{array}$ & $\begin{array}{l}\text { Meth } \\
1059.9 \\
1625.9 \\
1934.6 \\
2058.2 \\
2110.5 \\
2098.6\end{array}$ & $\begin{array}{c}\text { Methano } \\
0.5501 \\
0.5862 \\
0.6157 \\
0.6568 \\
0.7033 \\
0.7517\end{array}$ & $\begin{array}{c}(1)+\mathrm{Hex} \\
2063.2 \\
2013.4 \\
1931.8 \\
1836.4 \\
1713.4 \\
1546.7\end{array}$ & $\begin{array}{l}\text { (2) } \\
0.7971 \\
0.8450 \\
0.8923 \\
0.9292 \\
0.9665\end{array}$ & $\begin{array}{r}1382.0 \\
1175.4 \\
916.9 \\
640.1 \\
374.8\end{array}$ \\
\hline $\begin{array}{l}0.0920 \\
0.2090 \\
0.3175 \\
0.4075 \\
0.4677\end{array}$ & $\begin{array}{r}\text { Eth } \\
448.8 \\
955.5 \\
1274.2 \\
1447.5 \\
1522.9\end{array}$ & $\begin{array}{c}\text { Methanoa } \\
0.5161 \\
0.5681 \\
0.6185 \\
0.6714 \\
0.7272\end{array}$ & $\begin{array}{c}(1)+\text { Hex } \\
1539.9 \\
1525.3 \\
1437.6 \\
1335.8 \\
1198.6\end{array}$ & $\begin{array}{l}(2) \\
0.7841 \\
0.8430 \\
0.9022 \\
0.9514\end{array}$ & $\begin{array}{r}1015.9 \\
787.1 \\
531.1 \\
305.2\end{array}$ \\
\hline $\begin{array}{l}0.0969 \\
0.1860 \\
0.2656 \\
0.3316 \\
0.3921\end{array}$ & $\begin{array}{r}\text { Prop } \\
492.5 \\
782.6 \\
983.2 \\
1105.3 \\
1178.1\end{array}$ & $\begin{array}{c}\text { Methano: } \\
0.4458 \\
0.4941 \\
0.5356 \\
0.5758 \\
0.6321\end{array}$ & $\begin{array}{c}(1)+\text { Hex } \\
1210.2 \\
1215.0 \\
1200.5 \\
1148.3 \\
1080.7\end{array}$ & $\begin{array}{l}(2) \\
0.6905 \\
0.7533 \\
0.8171 \\
0.8850 \\
0.9453\end{array}$ & $\begin{array}{l}964.0 \\
814.7 \\
643.2 \\
415.4 \\
191.6\end{array}$ \\
\hline $\begin{array}{l}0.0865 \\
0.1588 \\
0.2303 \\
0.2973 \\
0.3551\end{array}$ & $\begin{array}{l}\quad \text { But } \\
321.7 \\
562.4 \\
764.2 \\
905.2 \\
989.7\end{array}$ & $\begin{array}{c}\text { Methanoa } \\
0.4081 \\
0.4540 \\
0.5114 \\
0.5606 \\
0.6177\end{array}$ & $\begin{array}{c}(1)+\text { Hex } \\
1037.9 \\
1056.9 \\
1051.2 \\
1017.7 \\
953.2\end{array}$ & $\begin{array}{l}\text { (2) } \\
0.6775 \\
0.7406 \\
0.8067 \\
0.8730 \\
0.9400\end{array}$ & $\begin{array}{l}859.8 \\
738.0 \\
584.5 \\
401.2 \\
212.8\end{array}$ \\
\hline \multicolumn{6}{|c|}{$T=318.15 \mathrm{~K}$} \\
\hline $\begin{array}{l}0.1003 \\
0.1895 \\
0.2842 \\
0.3713 \\
0.4495\end{array}$ & $\begin{array}{r}\text { Eth } \\
622.3 \\
1019.4 \\
1352.0 \\
1534.2 \\
1627.9\end{array}$ & $\begin{array}{l}\text { Methanoa } \\
0.5137 \\
0.5599 \\
0.5991 \\
0.6795 \\
0.7593\end{array}$ & $\begin{array}{c}(1)+\text { Hex } \\
1647.0 \\
1619.1 \\
1565.8 \\
1409.9 \\
1175.2\end{array}$ & $\begin{array}{l}\text { (2) } \\
0.8299 \\
0.8814 \\
0.9215 \\
0.9660\end{array}$ & $\begin{array}{l}902.3 \\
646.8 \\
439.8 \\
213.2\end{array}$ \\
\hline $\begin{array}{l}0.0848 \\
0.1889 \\
0.2934 \\
0.3854\end{array}$ & $\begin{array}{r}\text { Prop } \\
472.8 \\
845.7 \\
1122.6 \\
1275.7\end{array}$ & $\begin{array}{c}\text { Methano } \\
0.4624 \\
0.5210 \\
0.5945 \\
0.6631\end{array}$ & $\begin{array}{c}(1)+\text { Hex } \\
1340.9 \\
1338.6 \\
1291.9 \\
1190.3\end{array}$ & $\begin{array}{l}(2) \\
0.7368 \\
0.8154 \\
0.8906 \\
0.9523\end{array}$ & $\begin{array}{r}1025.1 \\
793.7 \\
518.0 \\
248.6\end{array}$ \\
\hline $\begin{array}{l}0.0808 \\
0.1626 \\
0.2415 \\
0.3110 \\
0.3823\end{array}$ & $\begin{array}{r}\text { But } \\
440.3 \\
704.8 \\
907.6 \\
1035.6 \\
1119.8\end{array}$ & $\begin{array}{l}\text { Methanoa } \\
0.4464 \\
0.4882 \\
0.5104 \\
0.5661 \\
0.6300\end{array}$ & $\begin{array}{c}(1)+\mathrm{Hex} \\
1150.9 \\
1147.7 \\
1151.5 \\
1114.9 \\
1046.2\end{array}$ & $\begin{array}{l}(2) \\
0.7075 \\
0.7904 \\
0.8680 \\
0.9412\end{array}$ & $\begin{array}{l}916.1 \\
730.6 \\
505.7 \\
270.0\end{array}$ \\
\hline
\end{tabular}

"active" contribution of the compound referring the concentration, for the excess property studied, and at the same concentration. Therefore, the parameter $k$ depends on the property to be correlated. For the function $G_{\mathrm{m}}^{\mathrm{E}} / R T$ the parameter $k$ is just one more parameter in the data fitting process (referred to as $k_{\mathrm{g}}$ ), while for the properties $V_{\mathrm{m}}^{\mathrm{E}}$ and $H_{\mathrm{m}}^{\mathrm{E}}$, it is assigned a physical value is calculated as described below. To fit the data $\left(x_{1}, V_{\mathrm{m}}^{\mathrm{E}}\right)$, this parameter is represented as $k_{\mathrm{v}}$ and is calculated from the quotient of the molar volumes, $V_{\mathrm{m} . i}^{\circ}(T)$ of each of the pure compounds $i$ at the working temperature. The experimental data show that similar results are achieved when $k_{\mathrm{v}}$ is calculated as the quotient of volume parameters, $r_{i}$ for each of the components $i$ where $r_{i}=\sum v_{\mathrm{k}}^{(i)} R_{\mathrm{k}}$ in which $v_{\mathrm{k}}^{(i)}$ is the whole number that corresponds to the number of groups in the molecule of compound $i$. Parameters $R_{\mathrm{k}}$ correspond to the van der Waals group volume parameters reported in Bondi. ${ }^{21}$ Although similar results were obtained with this group contribution method, we calculate $k_{\mathrm{v}}$ using the molar volumes of the compounds because the empirical method does not take into account the structural change in the different types of compounds (such as the regioisomers) or the changes in working conditions (such as temperature).

The enthalpy of the mixtures resulting from molecular interactions and the energetic effect is directly related to the contact surfaces between the molecules. For the correlation of $\left(x_{1}, H_{\mathrm{m}}^{\mathrm{E}}\right)$ the $k$ parameter is designated $k_{\mathrm{h}}$, and in this case it corresponds to the quotient of the molecular surfaces of the substances involved in the system. Hence, the $k_{\mathrm{h}}$ values are obtained from a $k_{\mathrm{v}}$ value weighted with the quotients of theoretical parameters of area $q_{i}$ and volume $r_{i}$, as shown below:

$$
k_{\mathrm{h}}=\left(\frac{q_{2}}{q_{1}}\right)\left(\frac{V_{\mathrm{m}, 2}^{\circ}}{V_{\mathrm{m}, 1}^{\circ}}\right)^{2 / 3}\left(\frac{r_{1}}{r_{2}}\right)^{2 / 3}=k_{\mathrm{q}}\left(\frac{k_{\mathrm{v}}}{k_{\mathrm{r}}}\right)^{2 / 3}
$$

where $q_{i}=\sum v_{\mathrm{k}}^{(i)} Q_{\mathrm{k}}$ and the $Q_{\mathrm{k}}$ values are the van der Waals group area parameters, described in Bondi. ${ }^{21}$

The second column in Table 4 reports the values of $k_{\mathrm{v}}$ and $k_{\mathrm{h}}$ calculated by this method for the four systems studied here. It is seen that there are slight differences with the theoretical values $k_{\mathrm{r}}$ and $k_{\mathrm{q}}$, which become more pronounced with increasing temperature. This table also gives the coefficients $a_{i}$ of eq 1 , obtained by a least-squares procedure, and the standard deviations for each mixture, $\sigma\left(Y_{\mathrm{m}}^{\mathrm{E}}\right)$. To avoid confusion, Figures 1a and 2a show, respectively, the experimental dots of $V_{\mathrm{m}}^{\mathrm{E}}$ and the fitting curves, the former corresponding to temperatures (291.15 and 318.15) $\mathrm{K}$ and the latter to (298.15 and 308.15) $\mathrm{K}$. Figures $1 \mathrm{~b}$ and $2 \mathrm{~b}$ show the values of $V_{\mathrm{m}}^{\mathrm{E}}(x=0.5)$ as a function of $u, \mathrm{HCOOC}_{u} \mathrm{H}_{2 u+1}$, according to Figures $1 \mathrm{a}$ and $2 \mathrm{a}$, respectively, together with the values found in the literature given for purposes of comparison. A difference of $V_{\mathrm{m}}^{\mathrm{E}}(x=$ 0.5 ) is observed for the mixture of ethyl methanoate + hexane at $318.15 \mathrm{~K}$, obtained in a previous work, ${ }^{3}$ with a value $6 \%$ higher than the one recorded here. In contrast, the value determined by this work in the mixture methyl methanoate + hexane at $298.15 \mathrm{~K}$ is higher than that determined previously in our laboratory, ${ }^{9}$ possibly due to using a different batch of reagent. Estimation of $V_{\mathrm{m}}^{\mathrm{E}}$ from the density produced a pronounced change in error distribution. Only slight differences were found in the values of $V_{\mathrm{m}}^{\mathrm{E}}$ of the other mixtures.

Similarly, it is possible to deduce some conclusions about the presentation and correlation of the excess enthalpies. Values of the parameters obtained for eq 1 are found in Table 4, which also give the values for mixtures of alkyl methanoates + hexane obtained in a previous work ${ }^{9,12}$ by applying the same equation. The experimental values and calculated values are shown in Figure $3 a$, while Figure $3 \mathrm{~b}$ shows the equimolar values corresponding to the three temperatures.

Some interesting conclusions can be drawn from the results obtained. On one hand, the expansive effects of the mixtures studied are noteworthy, as reflected by the positive value of the $\left(\partial V_{\mathrm{m}}^{\mathrm{E}} / \partial T\right)_{p, x}$ coefficient, indicating that the thermal expansion of the solution increases with temperature. The reduced expansion with increasing length of the alkyl chain of the methanoate can be explained among other reasons by the better accommodation of the molecules of inert solvent (hexane) between those of the ester. The same effects can be observed for the enthalpies, which are endothermic in all cases, and with $\left(\partial H_{\mathrm{m}}^{\mathrm{E}} / \partial T\right)_{p, x}>0$. In spite of the fact that a previous work ${ }^{9}$ demonstrated the presence of bonds by hydrogen bridges in the alkyl methanoates with self-association effects, these effects are not very important as compared to other predominant ones, such as van der Waals attractions and dipole-dipole forces. Specifically, self-association effects can be significantly observed in the mixture with methyl methanoate, although all the effects 
Table 4. Coefficients and Standard Deviations, $\sigma$, Obtained Using Equation 1 To Correlate the Excess Properties $V_{\mathrm{m}}^{\mathrm{E}}$ and $H_{\mathrm{m}}^{\mathrm{E}}$

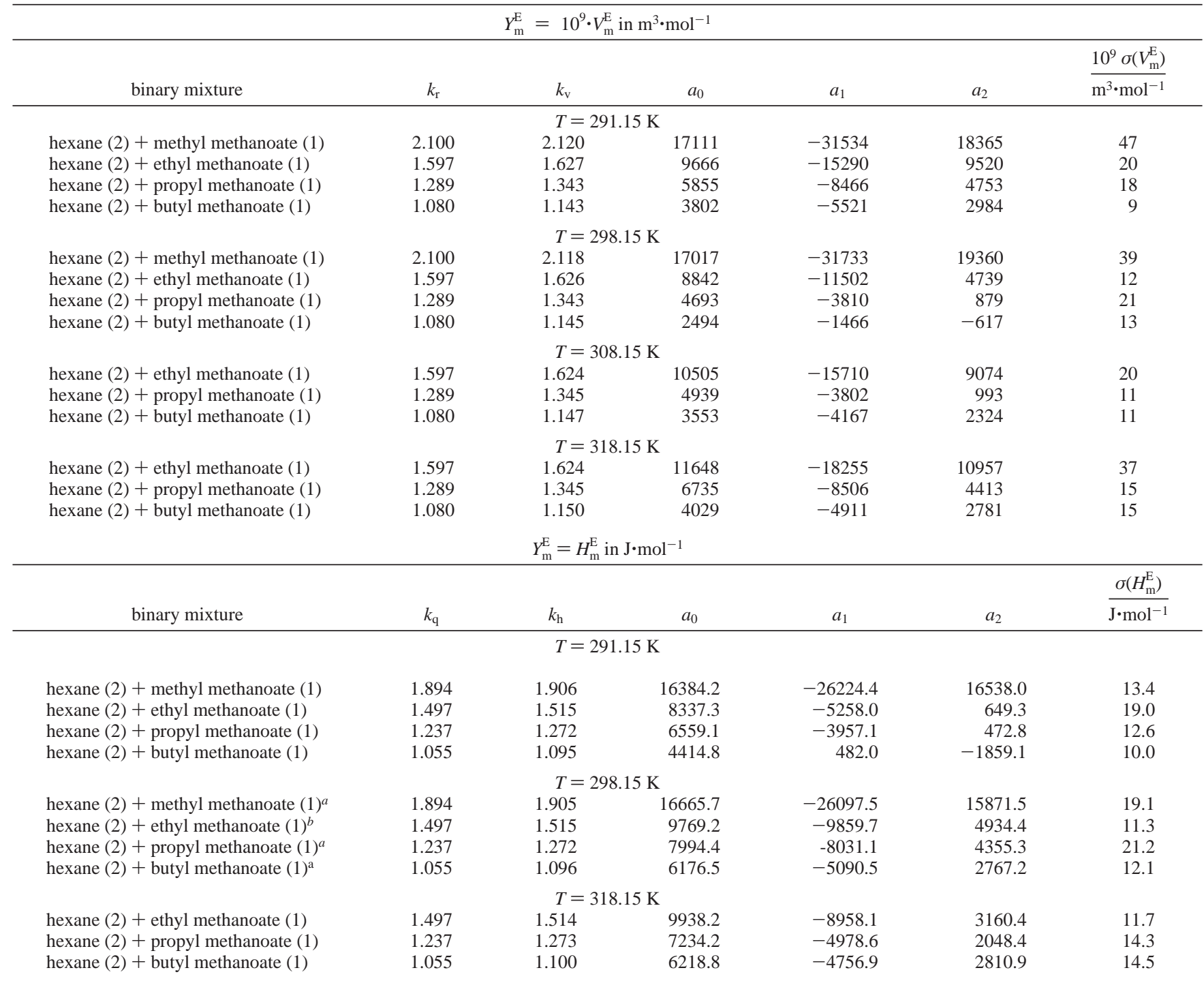

${ }^{a}$ Coefficients obtained using experimental values from ref $9 .{ }^{b}$ Coefficients obtained using experimental values from ref 12.
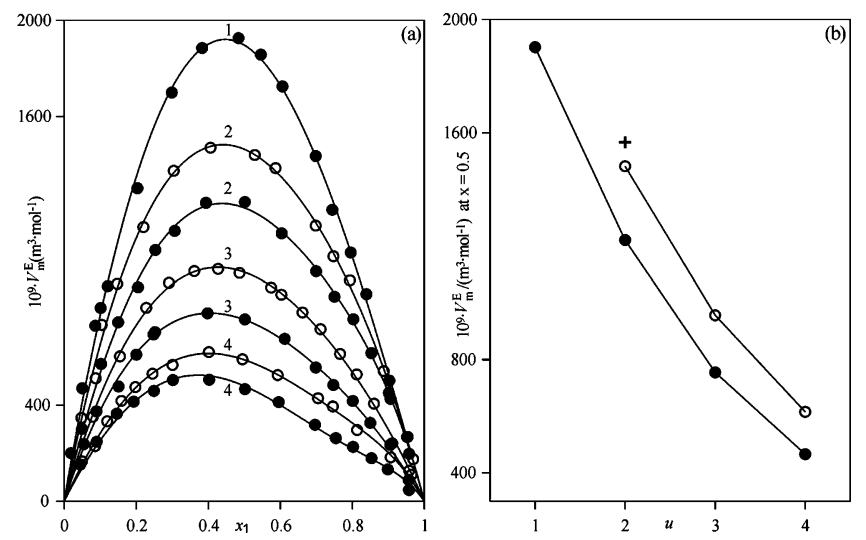

Figure 1. (a) Experimental values and correlation curves of $V_{\mathrm{m}}^{\mathrm{E}}$ vs $x_{1}$ for binary mixtures $\mathrm{HCOO}\left(\mathrm{CH}_{2}\right)_{u-l} \mathrm{CH}_{3}$ (1) $+\mathrm{CH}_{3}\left(\mathrm{CH}_{2}\right)_{4} \mathrm{CH}_{3}$ (2). Labels indicate $u$ values. (b) Variation of equimolar volume as a function of $u$ and temperature: ๑, at $291.15 \mathrm{~K}$; O, at $318.15 \mathrm{~K}$; +, values from ref 3 .

mentioned diminish with increased length of the alkanolic chain of the methanoate, reflected by the diminishing values of the properties studied (see Figures 1 to 3 ).

Vapor Pressures. The vapor pressure data used for pure compounds significantly affect the value that characterizes VLE, so it is usual to measure this property using the same
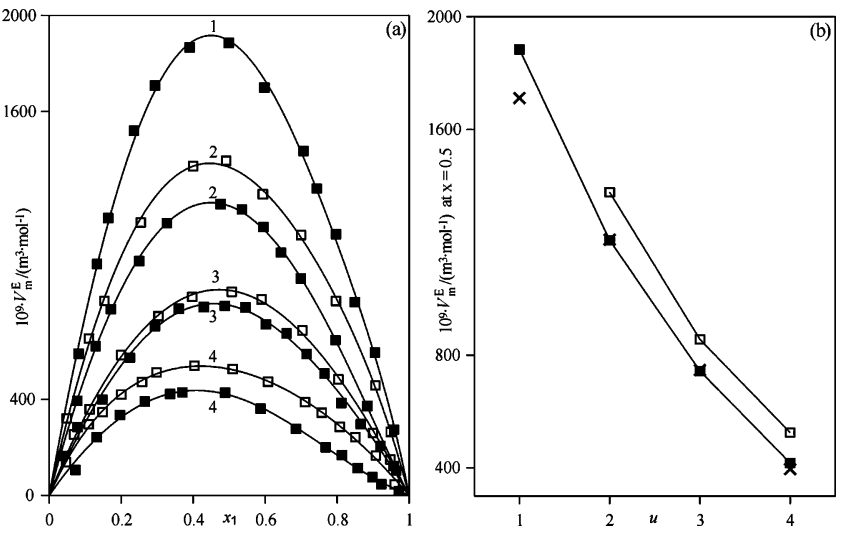

Figure 2. (a) Experimental values and correlation curves of $V_{\mathrm{m}}^{\mathrm{E}}$ vs $x_{1}$ for binary mixtures $\mathrm{HCOO}\left(\mathrm{CH}_{2}\right)_{u-l} \mathrm{CH}_{3}$ (1) $+\mathrm{CH}_{3}\left(\mathrm{CH}_{2}\right)_{4} \mathrm{CH}_{3}$ (2). Labels indicate $u$ values. (b) Variation of equimolar volume as a function of $u$ and temperature: $\mathbf{\square}$, at $298.15 \mathrm{~K} ; \square$, at $308.15 \mathrm{~K} ; \times$, values from ref 9 .

experimental apparatus as that used for the VLE determination. Experimental values of $\left(T, p_{i}\right)$ for the substances studied here have been obtained in our laboratory and reported in previous publications. ${ }^{2,5-7,22}$ All of these were correlated with Antoine's equation, with the constants given in Table 5. Figure 4 shows the vapor pressure lines for the alkyl methanoates and hexane 

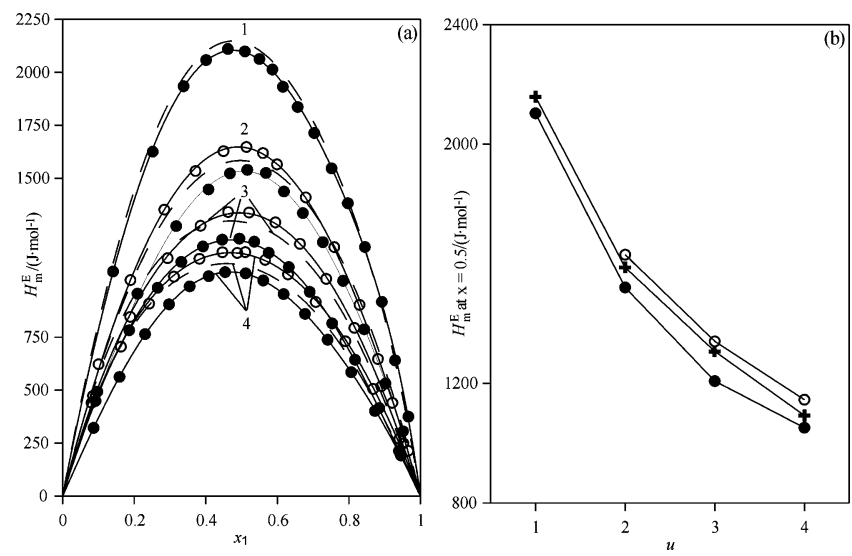

Figure 3. (a) Experimental values and correlation curves of $H_{\mathrm{m}}^{\mathrm{E}}$ vs $x_{1}$ for binary mixtures $\mathrm{HCOO}\left(\mathrm{CH}_{2}\right)_{u-l} \mathrm{CH}_{3}$ (1) $+\mathrm{CH}_{3}\left(\mathrm{CH}_{2}\right)_{4} \mathrm{CH}_{3}$ (2). Labels indicate $u$ values. $\bullet$, at $291.15 \mathrm{~K}$; $\bigcirc$, at $318.15 \mathrm{~K}$; - - at $298.15 \mathrm{~K}$ (refs 9 and 12). (b) Variation of equimolar enthalpies as a function of $u$ and temperature: ๑, at $291.15 \mathrm{~K}$; +, at $298.15 \mathrm{~K}$; O, at $318.15 \mathrm{~K}$.

Table 5. Coefficients $A, B$, and $C$ of the Antoine Equation, $\log ($ $\left.\left.p_{i}^{0 / k P a}\right)=A-B /(T / K)-C\right]$ and Acentric Factors for Pure Compounds Used in This Work To Calculate the Activity Coefficients $^{a}$

\begin{tabular}{lcccccr}
\hline \multicolumn{1}{c}{ compound } & $A$ & $B$ & $C$ & $\omega$ & $\Delta T / \mathrm{K}$ & ref \\
\hline hexane & 5.96291 & 1141.62 & 53.22 & 0.297 & $295-360$ & 22 \\
& $(2.4828)$ & $(2.2488)$ & $(0.105)$ & & & 22 \\
methyl methanoate & 6.45012 & 1216.46 & 31.08 & 0.258 & $300-330$ & 5 \\
& $(3.0508)$ & $(2.9595)$ & $(0.013)$ & & & 5 \\
ethyl methanoate & 6.65073 & 1431.31 & 19.09 & 0.273 & $300-350$ & 2 \\
& $(2.9535)$ & $(2.7897)$ & $(0.040)$ & & & 2 \\
propyl methanoate & 6.10108 & 1200.66 & 60.54 & 0.306 & $315-375$ & 7 \\
& $(2.4738)$ & $(2.2119)$ & $(0.1148)$ & & & 7 \\
butyl methanoate & 6.49980 & 1488.43 & 48.10 & 0.382 & $345-400$ & 6 \\
& $(2.9533)$ & $(2.6613)$ & $(0.086)$ & & & 6
\end{tabular}

${ }^{a}$ Between parentheses are the coefficients $a, b$, and $c$ of the Antoine equation in the reduced form (eq 3 ).

in reduced coordinates using a similar expression to that of Antoine:

$$
\log p_{i, \mathrm{r}}^{\circ}=a-b /\left(T_{\mathrm{r}}-c\right)
$$

Table 5 reports in parentheses the values for $a, b$, and $c$ obtained by applying a linear regression to the quantities $\left(T_{\mathrm{r}}\right.$, $\left.p_{i, \mathrm{r}}^{\circ}\right)$ and using a least-squares procedure. Acentric factors were determined using their definition, $\omega=-\left(\log p_{i, \mathrm{r}}^{\circ}\right)_{\mathrm{T}_{\mathrm{r}}=0.7}-1$ and are also recorded in Table 5 and used in the treatment of equilibrium data.

Presentation of VLE Data. Table 6 reports values of ( $p, T$, $\left.x_{1}, y_{1}\right)$ in isobaric VLE at $p=(101.32 \pm 0.02) \mathrm{kPa}$ for the four binary systems $\left\{x_{1} \mathrm{HCOOC}_{u} \mathrm{H}_{2 u+1}(u=1\right.$ to 4$\left.)+x_{2} \mathrm{C}_{6} \mathrm{H}_{14}\right\}$ studied here. Activity coefficients were calculated with

$$
\ln \gamma_{i}=\ln \left(\frac{p y_{i}}{p_{i}^{\circ} x_{i}}\right)+\frac{\left(B_{i i}-V_{i}^{9}\left(p-p_{i}^{9}\right)\right.}{R T}+\frac{p}{R T} \delta_{i j} y_{j}^{2}
$$

which takes into account the nonideality of the vapor phase. In eq $4, \delta_{i j}=2 B_{i j}-B_{i i}-B_{j j}$ and the second virial coefficients for the pure compounds $\left(B_{i i}, B_{j j}\right)$ and their mixtures $\left(B_{i j}\right)$ were estimated by Tsonopoulos's correlation. ${ }^{23}$ This correlation contains a parameter $b$, the significance of which is exclusively associated with substances that present hydrogen bonds, although here a value of $b=0$ has been used, in spite of the fact that methanoates present molecular association ${ }^{9}$ in which case $b \neq 0$. This circumstance has not been taken into account in the estimation of the second virial coefficients of pure com-

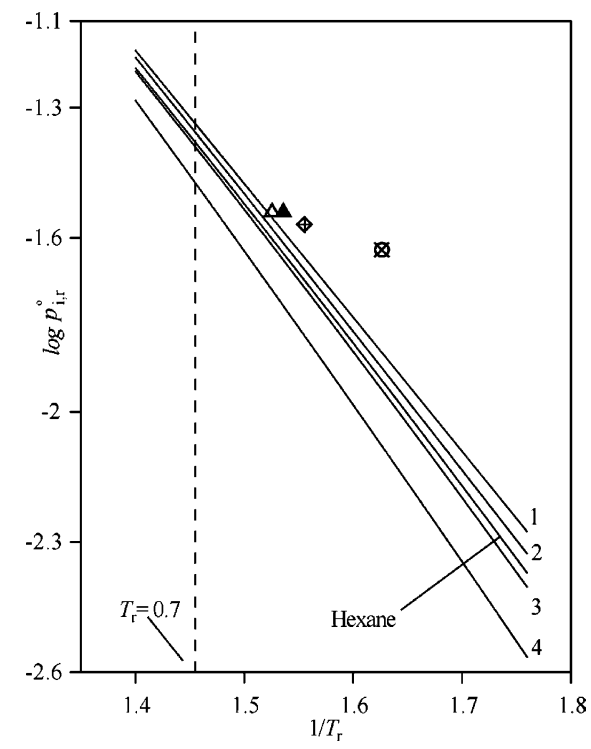

Figure 4. Vapor pressures lines in reduced coordinates for alkyl methanoates $\mathrm{HCOO}\left(\mathrm{CH}_{2}\right)_{u^{-l}} \mathrm{CH}_{3}$ and hexane. Labels indicate the $u$ values. Situation of azeotropic point in reduced coordinates for the binary (methyl methanoate + hexane): $\bigcirc$, this work; $\times$, from ref 8 ; (ethyl methanoate + hexane): $\diamond$, this work; + , from ref 3 ; and (propyl methanoate + hexane): $\triangle$, this work; $\mathbf{\Lambda}$, from ref 28 .

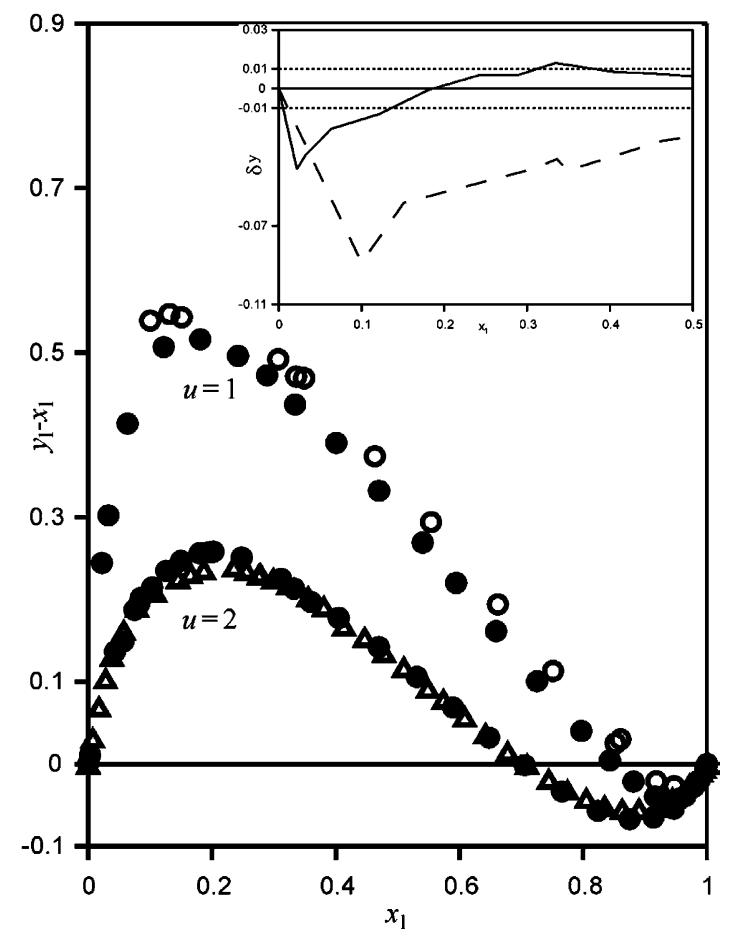

Figure 5. Representation of VLE experimental values $\left(y_{1}-x_{1}\right)$ vs $x_{1}$ for binary mixtures $\mathrm{HCOO}\left(\mathrm{CH}_{2}\right)_{u-1} \mathrm{CH}_{3}$ (1) $+\mathrm{CH}_{3}\left(\mathrm{CH}_{2}\right)_{4} \mathrm{CH}_{3}$ (2). Labels indicate $u$ values. $\bullet$, this work; $\bigcirc$, from ref 8 for $u=1$ and $\triangle$, from ref 3 for $u=2$. The inset figure shows the comparison between deviations $\delta y_{1}$ obtained in application of Fredenslund's method to our experimental values and those from ref 8 in the concentration range $[0,0.5]$.

pounds and mixtures, since values currently published in the literature do not publish $b$ values for esters, or more specifically, for methanoates. However, even when these are used, it is important to take into consideration that they only have a negligible effect on the final values of activity coefficients.

Molar volumes $V_{i}^{\circ}$ of pure compounds at equilibrium temperatures are calculated with Rackett's equation, modified by Spencer and Danner, ${ }^{24}$ using values of the $Z_{\mathrm{RA}}$ coefficient that appear in Reid et al. ${ }^{25}$ The vapor pressures $p_{i, \mathrm{r}}^{\circ}$ were calculated 
Table 6. Experimental Data and Calculated Quantities for the Isobaric VLE of the Binary Mixtures of Alkyl Methanoate (1) + Hexane (2) at $101.32 \mathrm{kPa}$

\begin{tabular}{|c|c|c|c|c|c|c|c|c|c|c|c|}
\hline$T / \mathrm{K}$ & $x_{1}$ & $y_{1}$ & $\gamma_{1}$ & $\gamma_{2}$ & $G_{\mathrm{m}}^{E} / R T$ & $T / \mathrm{K}$ & $x_{1}$ & $y_{1}$ & $\gamma_{1}$ & $\gamma_{2}$ & $G_{\mathrm{m}}^{E} / R T$ \\
\hline \multicolumn{12}{|c|}{ Methyl Methanoate (1) + Hexane (2) } \\
\hline 341.76 & 0.0000 & 0.0000 & & 1.000 & 0.000 & 303.08 & 0.6592 & 0.8204 & 1.325 & 2.055 & 0.431 \\
\hline 333.45 & 0.0220 & 0.2663 & 4.826 & 0.969 & 0.004 & 302.91 & 0.7253 & 0.8257 & 1.219 & 2.491 & 0.395 \\
\hline 331.00 & 0.0325 & 0.3347 & 4.406 & 0.962 & 0.011 & 302.77 & 0.7969 & 0.8369 & 1.130 & 3.172 & 0.332 \\
\hline 325.36 & 0.0634 & 0.4771 & 3.810 & 0.943 & 0.030 & 302.73 & 0.8429 & 0.8473 & 1.084 & 3.847 & 0.279 \\
\hline 315.65 & 0.1218 & 0.6286 & 3.556 & 1.009 & 0.163 & 302.75 & 0.8811 & 0.8597 & 1.051 & 4.669 & 0.227 \\
\hline 311.55 & 0.1809 & 0.6971 & 3.046 & 1.030 & 0.226 & 302.88 & 0.9160 & 0.8763 & 1.025 & 5.799 & 0.171 \\
\hline 308.20 & 0.2420 & 0.7380 & 2.705 & 1.096 & 0.311 & 303.07 & 0.9367 & 0.8903 & 1.012 & 6.774 & 0.132 \\
\hline 306.72 & 0.2890 & 0.7615 & 2.462 & 1.128 & 0.346 & 303.36 & 0.9585 & 0.9172 & 1.008 & 7.715 & 0.092 \\
\hline 305.93 & 0.3342 & 0.7711 & 2.217 & 1.193 & 0.384 & 303.85 & 0.9781 & 0.9501 & 1.005 & 8.646 & 0.052 \\
\hline 304.76 & 0.4008 & 0.7910 & 1.977 & 1.269 & 0.416 & 304.11 & 0.9872 & 0.9657 & 1.002 & 10.068 & 0.032 \\
\hline 303.99 & 0.4699 & 0.8020 & 1.758 & 1.403 & 0.444 & 304.55 & 0.9979 & 0.9921 & 1.003 & 13.898 & 0.008 \\
\hline 303.53 & 0.5404 & 0.8095 & 1.569 & 1.586 & 0.455 & 304.70 & 1.0000 & 1.0000 & 1.000 & & 0.000 \\
\hline 303.30 & 0.5945 & 0.8146 & 1.447 & 1.766 & 0.450 & & & & & & \\
\hline \multicolumn{12}{|c|}{ Ethyl Methanoate (1) + Hexane (2) } \\
\hline 341.76 & 0.0000 & 0.0000 & & 1.000 & 0.000 & 325.60 & 0.3595 & 0.5566 & 1.637 & 1.160 & 0.272 \\
\hline 341.41 & 0.0028 & 0.0134 & 3.076 & 0.998 & 0.001 & 324.84 & 0.4048 & 0.5823 & 1.560 & 1.207 & 0.292 \\
\hline 337.13 & 0.0431 & 0.1796 & 3.047 & 0.986 & 0.035 & 324.22 & 0.4694 & 0.6114 & 1.448 & 1.287 & 0.306 \\
\hline 335.90 & 0.0569 & 0.2058 & 2.748 & 1.006 & 0.064 & 323.81 & 0.5308 & 0.6366 & 1.347 & 1.381 & 0.309 \\
\hline 334.85 & 0.0747 & 0.2620 & 2.752 & 0.985 & 0.062 & 323.53 & 0.5895 & 0.6580 & 1.265 & 1.500 & 0.305 \\
\hline 334.37 & 0.0820 & 0.2763 & 2.684 & 0.989 & 0.071 & 323.38 & 0.6478 & 0.6798 & 1.195 & 1.646 & 0.291 \\
\hline 334.12 & 0.0849 & 0.2867 & 2.711 & 0.986 & 0.071 & 323.31 & 0.7054 & 0.7038 & 1.139 & 1.825 & 0.269 \\
\hline 332.97 & 0.1033 & 0.3178 & 2.561 & 0.998 & 0.095 & 323.39 & 0.7656 & 0.7323 & 1.089 & 2.068 & 0.236 \\
\hline 331.63 & 0.1260 & 0.3608 & 2.488 & 1.002 & 0.116 & 323.66 & 0.8236 & 0.7667 & 1.050 & 2.373 & 0.193 \\
\hline 330.46 & 0.1497 & 0.3964 & 2.388 & 1.010 & 0.139 & 324.11 & 0.8749 & 0.8078 & 1.025 & 2.716 & 0.147 \\
\hline 329.30 & 0.1799 & 0.4361 & 2.270 & 1.017 & 0.161 & 324.67 & 0.9134 & 0.8483 & 1.012 & 3.040 & 0.107 \\
\hline 328.72 & 0.1959 & 0.4535 & 2.209 & 1.025 & 0.175 & 325.38 & 0.9463 & 0.8920 & 1.003 & 3.409 & 0.068 \\
\hline 328.48 & 0.2022 & 0.4603 & 2.189 & 1.028 & 0.181 & 325.93 & 0.9657 & 0.9271 & 1.002 & 3.537 & 0.046 \\
\hline 327.17 & 0.2481 & 0.4991 & 2.020 & 1.058 & 0.217 & 326.56 & 0.9835 & 0.9619 & 1.000 & 3.764 & 0.022 \\
\hline 326.06 & 0.3113 & 0.5365 & 1.795 & 1.110 & 0.254 & 326.94 & 0.9938 & 0.9847 & 1.000 & 3.973 & 0.009 \\
\hline 325.85 & 0.3324 & 0.5455 & 1.721 & 1.131 & 0.263 & 327.33 & 1.0000 & 1.0000 & 1.000 & & 0.000 \\
\hline \multicolumn{12}{|c|}{ Propyl Methanoate (1) + Hexane (2) } \\
\hline 341.76 & 0.0000 & 0.0000 & & 1.000 & 0.000 & 340.85 & 0.6041 & 0.4490 & 1.126 & 1.430 & 0.213 \\
\hline 341.25 & 0.0261 & 0.0413 & 2.375 & 0.998 & 0.021 & 341.25 & 0.6421 & 0.4725 & 1.100 & 1.497 & 0.205 \\
\hline 340.72 & 0.0523 & 0.0796 & 2.324 & 1.001 & 0.045 & 341.82 & 0.6923 & 0.5007 & 1.060 & 1.620 & 0.189 \\
\hline 340.25 & 0.0810 & 0.1159 & 2.219 & 1.005 & 0.069 & 342.56 & 0.7229 & 0.5280 & 1.044 & 1.664 & 0.172 \\
\hline 339.74 & 0.1243 & 0.1623 & 2.059 & 1.015 & 0.103 & 344.00 & 0.7894 & 0.5875 & 1.014 & 1.834 & 0.139 \\
\hline 339.35 & 0.1753 & 0.2085 & 1.900 & 1.031 & 0.138 & 345.05 & 0.8270 & 0.6324 & 1.007 & 1.930 & 0.119 \\
\hline 339.12 & 0.2371 & 0.2532 & 1.719 & 1.059 & 0.172 & 346.01 & 0.8549 & 0.6698 & 0.999 & 2.010 & 0.101 \\
\hline 339.10 & 0.3010 & 0.2924 & 1.564 & 1.096 & 0.199 & 347.25 & 0.8844 & 0.7163 & 0.992 & 2.092 & 0.079 \\
\hline 339.20 & 0.3598 & 0.3243 & 1.446 & 1.140 & 0.216 & 348.45 & 0.9116 & 0.7641 & 0.988 & 2.199 & 0.059 \\
\hline 339.37 & 0.4139 & 0.3524 & 1.357 & 1.187 & 0.227 & 349.55 & 0.9347 & 0.8115 & 0.988 & 2.307 & 0.044 \\
\hline 339.64 & 0.4643 & 0.3777 & 1.285 & 1.238 & 0.231 & 350.67 & 0.9533 & 0.8545 & 0.985 & 2.413 & 0.027 \\
\hline 340.07 & 0.5286 & 0.4084 & 1.202 & 1.320 & 0.228 & 352.60 & 0.9813 & 0.9370 & 0.988 & 2.475 & 0.005 \\
\hline 340.42 & 0.5660 & 0.4300 & 1.168 & 1.367 & 0.224 & 353.92 & 1.0000 & 1.0000 & 1.000 & & 0.000 \\
\hline \multicolumn{12}{|c|}{ Butyl Methanoate (1) + Hexane (2) } \\
\hline 341.76 & 0.0000 & 0.0000 & & 1.000 & 0.000 & 357.40 & 0.7269 & 0.3649 & 1.014 & 1.494 & 0.120 \\
\hline 342.03 & 0.0198 & 0.0133 & 2.383 & 0.997 & 0.014 & 358.87 & 0.7569 & 0.3941 & 0.999 & 1.541 & 0.105 \\
\hline 342.36 & 0.0481 & 0.0288 & 2.097 & 1.001 & 0.036 & 360.60 & 0.7888 & 0.4340 & 0.996 & 1.584 & 0.094 \\
\hline 342.84 & 0.0948 & 0.0531 & 1.925 & 1.011 & 0.072 & 362.78 & 0.8226 & 0.4801 & 0.982 & 1.637 & 0.072 \\
\hline 343.43 & 0.1370 & 0.0736 & 1.805 & 1.020 & 0.098 & 365.52 & 0.8631 & 0.5498 & 0.979 & 1.715 & 0.055 \\
\hline 344.42 & 0.2194 & 0.1071 & 1.579 & 1.056 & 0.142 & 368.22 & 0.8980 & 0.6258 & 0.981 & 1.790 & 0.042 \\
\hline 345.84 & 0.2995 & 0.1373 & 1.405 & 1.091 & 0.163 & 371.76 & 0.9357 & 0.7322 & 0.985 & 1.866 & 0.026 \\
\hline 347.23 & 0.3863 & 0.1661 & 1.251 & 1.156 & 0.175 & 374.24 & 0.9605 & 0.8169 & 0.991 & 1.959 & 0.018 \\
\hline 348.83 & 0.4556 & 0.1986 & 1.195 & 1.197 & 0.179 & 376.08 & 0.9770 & 0.8824 & 0.995 & 2.071 & 0.012 \\
\hline 349.97 & 0.5182 & 0.2216 & 1.125 & 1.272 & 0.177 & 377.36 & 0.9869 & 0.9299 & 0.998 & 2.104 & 0.008 \\
\hline 351.93 & 0.5828 & 0.2609 & 1.097 & 1.320 & 0.170 & 378.49 & 0.9951 & 0.9718 & 1.000 & 2.206 & 0.004 \\
\hline 353.35 & 0.6230 & 0.2872 & 1.073 & 1.355 & 0.159 & 380.13 & 1.0000 & 1.0000 & 1.000 & & 0.000 \\
\hline 355.27 & 0.6807 & 0.3218 & 1.028 & 1.445 & 0.137 & & & & & & \\
\hline
\end{tabular}

with Antoine's equation, using the constants $A, B$, and $C$ of Table 5. With the activity coefficients obtained, values of Gibbs adimensional function $G_{\mathrm{m}}^{\mathrm{E}}=\sum x_{i} \ln \gamma_{i}$ were estimated and are reported in the last column of Table 6 for each binary system. The $\gamma_{i}$ values show that the systems present a strong deviation from ideal values, especially for the methyl methanoate system (due to a greater molecular self-association). The deviation becomes less pronounced with increasing ester chain to give rise to a quasi-ideal behavior for butyl methanoate, producing a decreasing order of $\gamma_{i}$ in the order methyl $>$ ethyl $>$ propyl $>$ butyl.
The four systems studied satisfy the global condition suggested by Fredenslund, ${ }^{26} \bar{\delta}=\sum_{i}\left(y_{i, \exp }-y_{i, \text { calc }}\right) / N \leq 0.01$. Figure 5 shows the concentrations, in the form of $\left(y_{1}-x_{1}\right)$ vs $x_{1}$, obtained for the binary systems \{methyl methanoate (1) or ethyl methanoate (1) + hexane(2) $\}$ with the data recorded in the literature for comparative purposes. The differences found for the system (ethyl methanoate + hexane) between data from Table 6 and those obtained previously in our laboratory ${ }^{3}$ are not significant. However, there are slight discrepancies for the mixture methyl methanoate + hexane with the values determined by Ogorodnikov et al., ${ }^{8}$ especially in the region of low 
Table 7. Experimental Azeotropic Coordinates $\left(x_{1 \mathrm{az}}, T_{\mathrm{az}}\right)$ at $p=$ $101.32 \mathrm{kPa}$ for Binary Mixtures of Alkyl Methanoate (1) + Hexane (2) and Comparison with Those Found in Literature, and Values Predicted by Two Versions of the UNIFAC Model ${ }^{15,16}$

\begin{tabular}{|c|c|c|c|}
\hline \multirow[b]{2}{*}{ mixture } & \multicolumn{2}{|c|}{$x_{1 \mathrm{az}}, T_{\mathrm{az}} / \mathrm{K}$} & \multirow[b]{2}{*}{ ref } \\
\hline & $\exp$ & lit & \\
\hline \multirow[t]{5}{*}{$\begin{array}{l}\text { methyl methanoate }(1)+ \\
\text { hexane }(2)\end{array}$} & $0.832,302.62$ & & this work \\
\hline & & $0.849,302.65$ & 8 \\
\hline & & non-azeotrope & 27 \\
\hline & & $0.790,301.54$ & 15 \\
\hline & & $0.768,300.25$ & 16 \\
\hline \multirow[t]{5}{*}{$\begin{array}{l}\text { ethyl methanoate (1) }+ \\
\text { hexane (2) }\end{array}$} & $0.703,323.32$ & & this work \\
\hline & & $0.709,323.21$ & 3 \\
\hline & & $0.703,322.65$ & 27 \\
\hline & & $0.660,321.46$ & 15 \\
\hline & & $0.651,320.23$ & 16 \\
\hline \multirow[t]{5}{*}{$\begin{array}{l}\text { propyl methanoate }(1)+ \\
\text { hexane }(2)\end{array}$} & $0.283,339.10$ & & this work \\
\hline & & $0.290,336.75$ & 28 \\
\hline & & $0.196,336.15$ & 28 \\
\hline & & $0.306,337.42$ & 15 \\
\hline & & $0.336,336.23$ & 16 \\
\hline
\end{tabular}

ester concentrations; these values do not verify with the consistency method proposed by Frendenslund et al. ${ }^{26}$ residual values are shown in the insert in Figure 5. Figure $6 \mathrm{a}-\mathrm{d}$ shows the set of data obtained directly $\left(T, x_{1}, y_{1}\right)$ for each binary system ( $x_{1}$ alkyl methanoate $+x_{2}$ hexane).Analysis of these gives rise to the following observations.

Three of the four systems studied present an azeotropic point, which is compared with the one reported in available compilations (Gmehling et al., ${ }^{27}$ Horsley $^{28}$ ) in Table 7. For the mixture methyl methanoate +hexane the value is similar to that determined by Ogorodnikov et al., ${ }^{8}$ although Lecat (see Gmehling et al. ${ }^{27}$ ) estimated the nonexistence of an azeotrope for this mixture. In the mixture ethyl methanoate + hexane the values calculated in this work and those recorded in the literature are similar to those recorded by Gmehling et al. ${ }^{27}$ The greatest difference is observed for the azeotrope calculated for the mixture propyl methanoate + hexane, especially at the temperatures reported in the literature. Figure 4 shows the situation of the azeotropic points using reduced coordinates, which have been represented together with the vapor pressure lines of the pure compounds in this work, alkyl methanoates and hexane. The pseudocritical properties were estimated as geometric mean of the critical properties of the pure compounds.

Figure $7 \mathrm{a}-\mathrm{d}$ shows other characteristic values of VLE, such as $\gamma_{i}$ and $G_{\mathrm{m}}^{\mathrm{E}} / R T$, as a function of the concentration of the corresponding alkyl methanoate $x_{1}$; the pertinent numerical values are given in Table 6 . The correlation and prediction of these values is given below.

\section{Treatment of VLE Data}

The values of Gibbs function, $G_{\mathrm{m}}^{\mathrm{E}}=G_{\mathrm{m}}^{\mathrm{E}}\left(x_{1}, T\right)$, obtained for isobaric equilibrium were correlated by a simple mathematical equation already used in previous works ${ }^{5-7}$ and having the following form:

$$
\frac{G_{\mathrm{m}}^{\mathrm{E}}}{R T}\left(x_{1}, T\right)=z_{1}\left(1-z_{1}\right) \sum_{i=0}^{m} a_{\mathrm{i}} z_{1}{ }^{i}
$$

where $a_{i}$ can be written as a function of temperature, and $z_{1}$ is the active fraction of the corresponding methanoate in each of the binary mixtures that would be expressed as a function of the molar fraction of the same ester by a well-known relationship. However, for the correlation of Gibbs function (eq 5) with the temperature, it can be established that coefficients $a_{i}$ are dependent on temperature as follows:

$$
a_{i}=\sum_{j=0}^{3} A_{i j} T^{j-1}=\frac{A_{i 0}}{T}+A_{i 1}+A_{i 2} T
$$

The number of coefficients $A_{i j}$ in eq 6 can be reduced when over-parametrization is not required. After defining the adimen-

Table 8. Activity Coefficients at Infinite Dilution Obtained for Compounds in Binary Mixtures Alkyl Methanoate (1) + Hexane (2), Estimated

\begin{tabular}{|c|c|c|c|c|c|}
\hline & \multicolumn{2}{|c|}{$\begin{array}{c}\text { methyl } \\
\text { methanoate }(1)+ \\
\text { hexane }(2)\end{array}$} & $\begin{array}{c}\text { ethyl } \\
\text { methanoate }(1)+ \\
\text { hexane (2) }\end{array}$ & $\begin{array}{c}\text { propyl } \\
\text { methanoate }(1)+ \\
\text { hexane }(2)\end{array}$ & $\begin{array}{c}\text { butyl } \\
\text { methanoate }(1)+ \\
\text { hexane (2) }\end{array}$ \\
\hline$\gamma_{1}^{\infty}$ & 4.51 & $5.32^{a}$ & 3.10 & 2.52 & 2.23 \\
\hline$\gamma_{2}^{\infty}$ & 11.84 & $12.08^{a}$ & 4.04 & 2.42 & 1.06 \\
\hline
\end{tabular}
by Equations 10 and 11

${ }^{a} \operatorname{Ref} 29$.

Table 9. Parameters for Equations 5 and 9 Obtained in Correlation of VLE Data of Binary Mixtures Alkyl Methanoate (1) + Hexane (2), and Standard Deviations Obtained for Activity Coefficients $\sigma\left(\ln \gamma_{i}\right)$, Nondimensional Gibbs Function $\sigma\left(G_{\mathrm{m}}^{\mathrm{E}} / R T\right)$, and Excess Enthalpies $\sigma\left(H_{\mathrm{m}}^{\mathrm{E}}\right)$

\begin{tabular}{|c|c|c|c|c|}
\hline & $\begin{array}{c}\text { methyl } \\
\text { methanoate (1) }+ \\
\text { hexane (2) }\end{array}$ & $\begin{array}{c}\text { ethyl } \\
\text { methanoate (1) }+ \\
\text { hexane (2) }\end{array}$ & $\begin{array}{c}\text { propyl } \\
\text { methanoate }(1)+ \\
\text { hexane (2) }\end{array}$ & $\begin{array}{c}\text { butyl } \\
\text { methanoate (1) }+ \\
\text { hexane (2) }\end{array}$ \\
\hline$A_{00}$ & -5.287 & 283.693 & -17.520 & -1521.303 \\
\hline$A_{10}$ & 259.651 & -104.962 & 123.261 & 6992.515 \\
\hline$A_{20}$ & -100.424 & -718.935 & 0.837 & 2624.108 \\
\hline$A_{01}$ & 6.231 & 2.723 & 4.739 & 14.173 \\
\hline$A_{11}$ & -4.152 & -1.345 & -4.919 & -49.966 \\
\hline$A_{21}$ & 2.269 & 5.498 & 1.694 & -13.608 \\
\hline$A_{02}$ & -0.013 & -0.007 & -0.009 & -0.028 \\
\hline$A_{12}$ & 0.006 & 0.004 & 0.010 & 0.083 \\
\hline$A_{22}$ & -0.002 & -0.009 & -0.004 & 0.017 \\
\hline$k$ & 1.109 & 1.098 & 1.448 & 1.514 \\
\hline$\sigma\left(\ln \gamma_{1}\right)$ & 0.027 & 0.013 & 0.021 & 0.016 \\
\hline$\sigma\left(\ln \gamma_{2}\right)$ & 0.057 & 0.016 & 0.031 & 0.015 \\
\hline$\sigma\left(G_{\mathrm{m}}^{\mathrm{E}} / R T\right)$ & 0.021 & 0.012 & 0.009 & 0.009 \\
\hline$\sigma\left(H_{\mathrm{m}}^{\mathrm{E}}\right)$ & 38.9 & 7.2 & 16.1 & 20.2 \\
\hline
\end{tabular}
in $\mathbf{J}^{\prime} \mathbf{m o l} \mathbf{l}^{-1}$ 

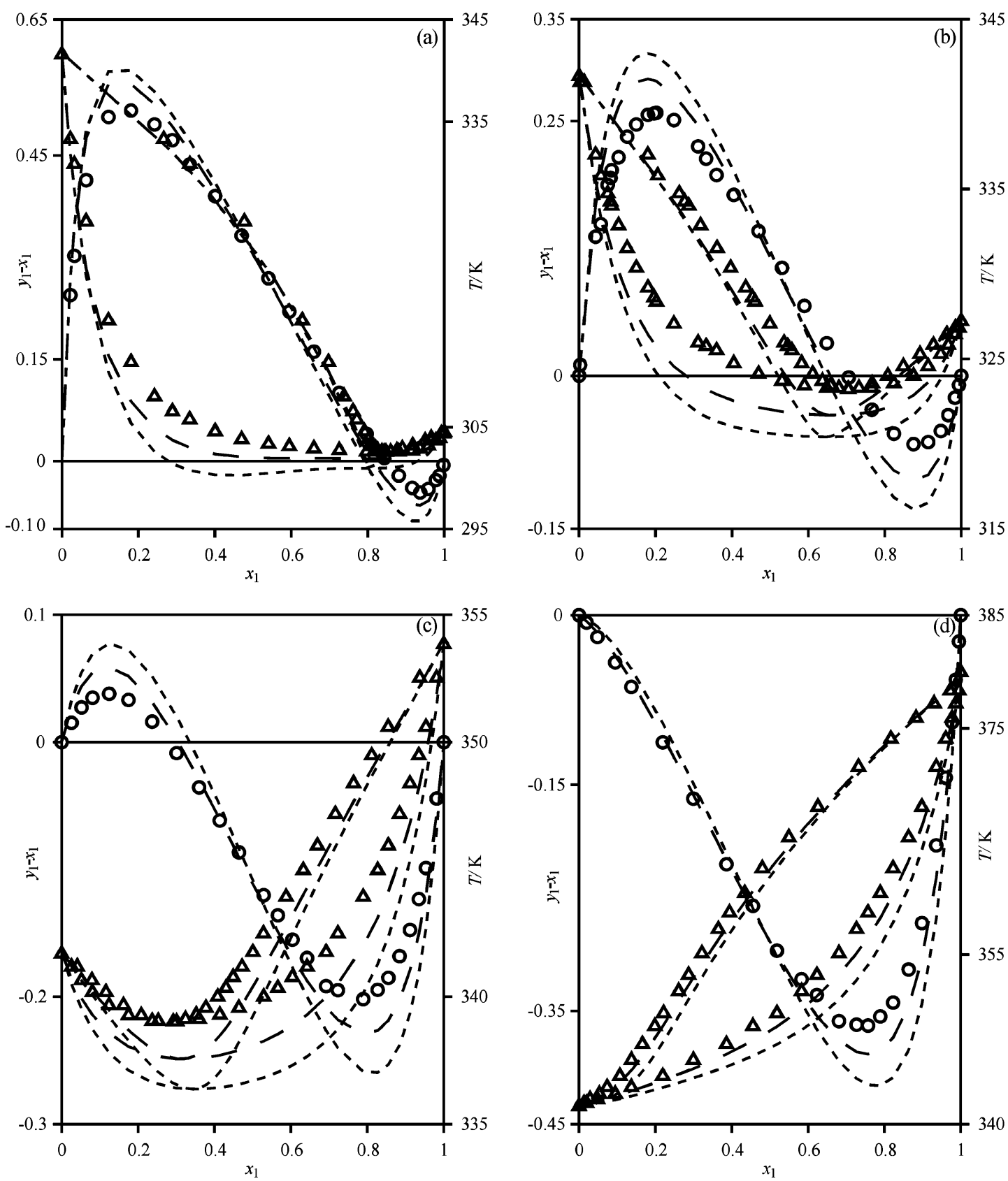

Figure 6. Representation of experimental VLE values: $\mathrm{O},\left(y_{1}-x_{1}\right)$ vs $x_{1}$ and $\triangle, T$ vs $x_{1}, y_{1}$ for binary mixtures $\mathrm{HCOO}\left(\mathrm{CH}_{2}\right)_{u-1} \mathrm{CH}_{3}(1)+\mathrm{C}_{6} \mathrm{CH}_{14}(2)$. (a) For $u=1$. (b) For $u=2$. (c) For $u=3$. (d) For $u=4$. Dashed lines represent the estimated curves with the UNIFAC model: -- , ref 15 ; - - -, ref 16 .

sional Gibbs function as $Q=G_{\mathrm{m}}^{\mathrm{E}} / R T$, the mathematical expressions for enthalpies and activity coefficients must be obtained, considering the direct relationships between these quantities.

Hence, for the enthalpies we have the following relationship:

$$
\begin{aligned}
& -\frac{H_{\mathrm{m}}^{\mathrm{E}}}{R T^{2}}=\left[\frac{\partial Q}{\partial T}\right]_{p, x}=z_{1}\left(1-z_{1}\right) \sum_{i=0}^{2}\left(\frac{\mathrm{d} a_{i}}{\mathrm{~d} T}\right) z_{1}{ }^{i}+ \\
& \left(\frac{\mathrm{d} z_{1}}{\mathrm{~d} k}\right)\left(\frac{\mathrm{d} k}{\mathrm{~d} T}\right)\left[\left(1-2 z_{1}\right) \sum_{i=0}^{2} a_{i} z_{1}{ }^{i}+z_{1}\left(1-z_{1}\right)\left(a_{1}+2 a_{2} z_{1}\right)\right]
\end{aligned}
$$

For the practical application of this equation, it can be assumed initially that the parameter $k$ is independent of temperature, which would cancel out the second addenda of the expression (eq 7). To determine the activity coefficients, we know that in a binary mixture where $i=1,2$ and taking into account that $z_{1}$ $=z_{1}\left(x_{1}\right)$ :

$$
\ln \gamma_{i}=Q+\left(1-x_{i}\right)\left(\frac{\partial Q}{\partial x_{i}}\right)_{p, T}=Q+\left(1-x_{i}\right)\left(\frac{\partial Q}{\partial z_{1}}\right)\left(\frac{\mathrm{d} z_{1}}{\mathrm{~d} x_{i}}\right)
$$

which in our case produces the following generic equation:

$$
\ln \gamma_{i}=z_{1}\left(1-z_{1}\right) \sum_{i=0}^{2} a_{\mathrm{i}} z_{1}{ }^{i}+\left(1-x_{i}\right)\left(\sum_{i=0}^{3}(i+1) b_{i}\right) k\left(\frac{z_{1}}{x_{1}}\right)^{2}
$$

where $b_{i}=a_{i}-a_{i-1} ; y 0 \leq a_{i} \leq 3$. The corresponding values of the activity coefficients at infinite dilution can be determined, respectively, by

$$
\begin{gathered}
\ln \gamma_{1}^{\infty}=\lim _{x \rightarrow 0} \gamma_{1} \equiv \lim _{z \rightarrow 0} \gamma_{1}=\frac{a_{0}}{k} \\
\ln \gamma_{2}^{\infty}=\lim _{x \rightarrow 1} \gamma_{2} \equiv \lim _{z \rightarrow 1} \gamma_{2}=k\left(a_{0}+a_{1}+a_{2}\right)
\end{gathered}
$$



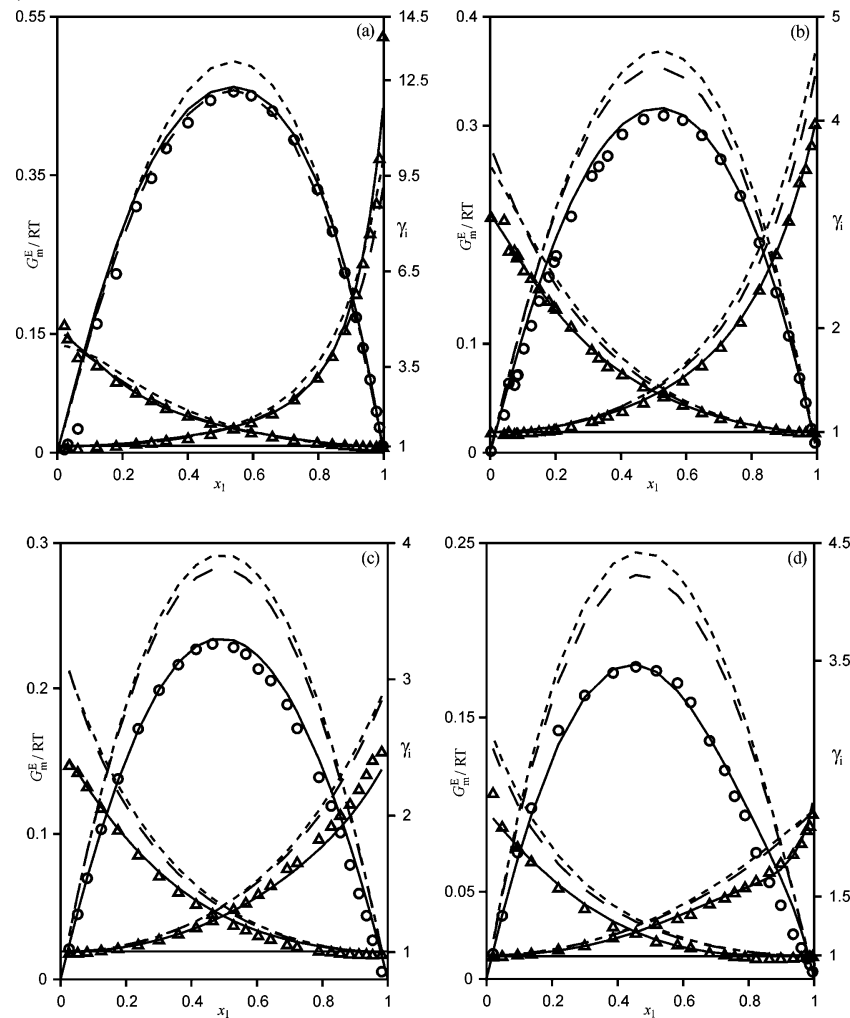

Figure 7. Representation of experimental and correlated curves $(-)$ for quantities $\bigcirc, G_{\mathrm{m}}^{\mathrm{E}} / R T$ vs $x_{1} ; \Delta, \gamma_{i}$ vs $x_{1}$ for the binary mixtures $\mathrm{HCOO}\left(\mathrm{CH}_{2}\right)_{u-1}$ $\mathrm{CH}_{3}$ (1) $+\mathrm{C}_{6} \mathrm{CH}_{14}$ (2). (a) For $u=1$. (b) For $u=2$. (c) For $u=3$. (d) For $u=4$. Dashed lines represent the values estimated by the UNIFAC model: -- , ref $15 ;---$, ref 16 .

Table 8 shows that the values obtained for the mixtures alkyl methanoates + hexane present high values of $\gamma_{i}^{\infty}$, especially in the methyl methanoate mixture (estimated values are similar to
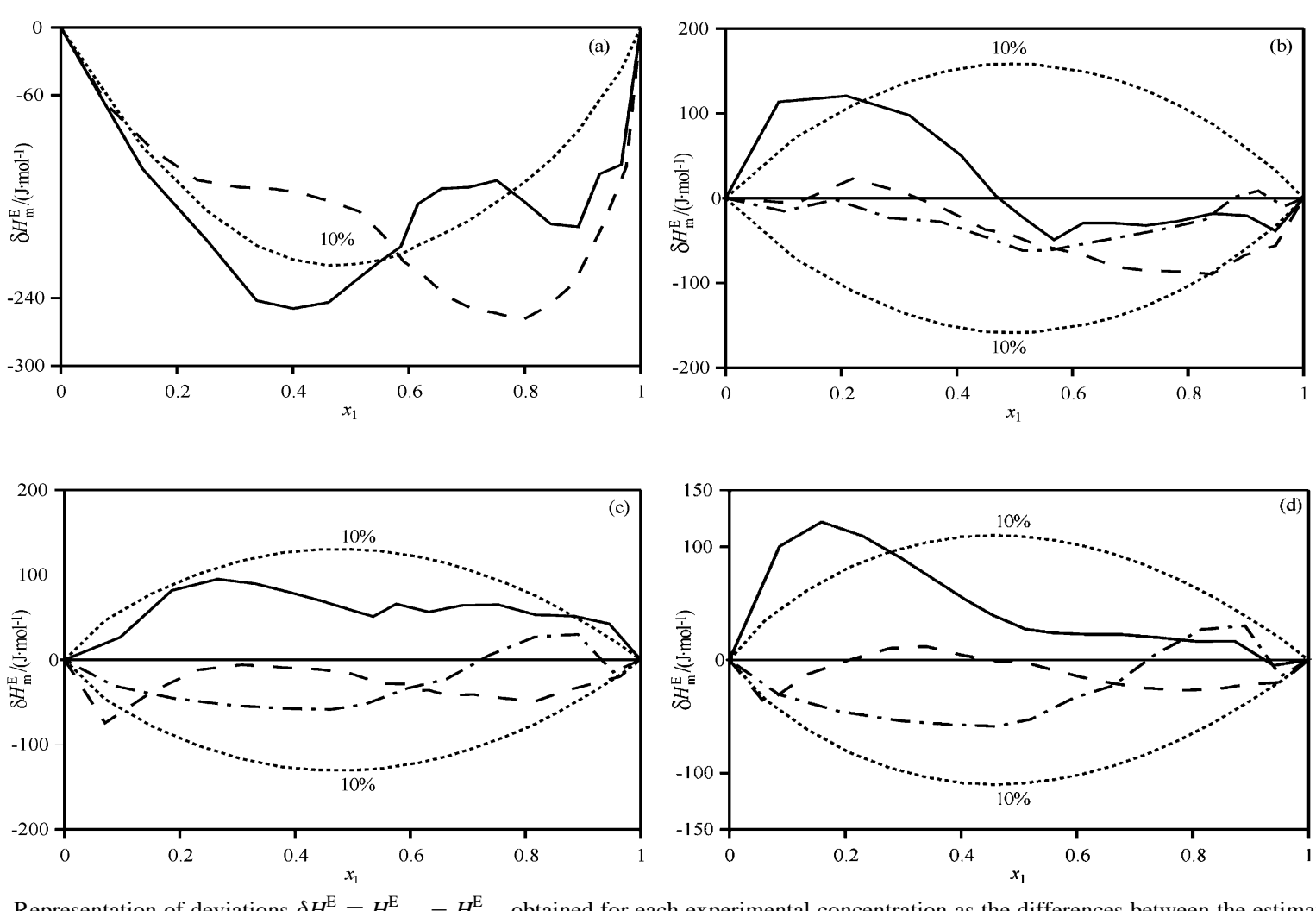

Figure 8. Representation of deviations $\delta H_{\mathrm{m}}^{\mathrm{E}}=H_{i, \text { calc }}^{\mathrm{E}}-H_{i, \text { exp }}^{\mathrm{E}}$ obtained for each experimental concentration as the differences between the estimated values by UNIFAC model ${ }^{16}$ and those experimental values: -, at $291.15 \mathrm{~K}$; - -, at $298.15 \mathrm{~K} ;-\cdot-$, at $318.15 \mathrm{~K}$. those published in the literature $\left.{ }^{29}\right)$, giving maximum values of nonideality in this case due to associative problems of the methanoate, which are most pronounced in methyl methanoate, steadily decreasing with increased alkanolic chain length as shown previously.

The set of eqs (5 to 9) allows the simultaneous correlation of experimental data with those data obtained from direct experimentation, such as the $\ln \gamma_{i}$, data of the adimensional Gibbs function $G_{\mathrm{m}}^{\mathrm{E}} / R T$, and the enthalpies, also in adimensional form, $H_{\mathrm{m}}^{\mathrm{E}} / R T$. If direct experimental values of $\ln \gamma_{i}^{\infty}$ are known, these could be added to the corresponding algorithm and their values introduced in the objective function produced.

One important aspect to take into account for optimum correlation of the experimental data is the definition of objective function $(\mathrm{OF})$. To minimize the $\mathrm{OF}$, this should take into account the discrepancies between experimental values and theoretical ones, in other words, the enthalpies $H_{\mathrm{m}}^{\mathrm{E}}$, and logarithms of the activity coefficients $\ln \gamma_{i}$. Since the Gibbs adimensional function is obtained from the activity coefficients and this has a statistically insignificant effect on the OF, it is not included in the proposed optimization equation:

$$
\mathrm{OF}=c_{1} \sigma\left(\ln \gamma_{1}\right)+c_{2} \sigma\left(\ln \gamma_{2}\right)+c_{3} \sigma\left(H_{\mathrm{m}}^{\mathrm{E}}\right)
$$

where $\sigma\left(\ln \gamma_{i}\right)$ and $\sigma\left(H_{\mathrm{m}}^{\mathrm{E}}\right)$, respectively, are the standard deviations of the activity coefficients and the excess enthalpies, generically defined as

$$
\sigma(E)=\left[\sum_{i=1}^{n}\left(E_{i, \exp }-E_{i, \mathrm{cal}}\right)^{2} /(n-1)\right]^{1 / 2}
$$

where $E$ represents the values of the amounts considered and $n$ the number of experiments. The coefficients $c_{i}$ are used to compensate for the quantities introduced in the OF. Afterward, the data for each of the binary systems were correlated by 
programming the previous equations with an algorithm in MATLAB. The pertinent numerical results are reported in Table 9. This table shows that the $A_{i 2}$ coefficients of the first three binary systems do not make a significant contribution, implying that eq 6 , as proposed here, can only be used to correlate data of the system butyl methanoate + hexane with an overparametrization in the other three cases. Coefficients are included in Table 9 to demonstrate this fact and to standardize the correlations of the systems studied. The quantitative evaluation for the different systems is done by the calculating standard deviations of data, which are considered to be acceptable in all cases. Qualitatively, the data are shown in Figure $7 a-d$ together with the experimental values where these can be obtained.

$\boldsymbol{V L E}$ Predictions. Two versions of the UNIFAC group contributions model have been used. The original version proposed by Fredenslund et al. ${ }^{26}$ with the set of more recent parameters proposed by Hansen et al. ${ }^{15}$ capable of estimating the $\gamma_{i}$ of our systems and the version of Gmehling et al. ${ }^{16}$ for which the $\gamma_{i}$ can also be used to achieve the enthalpies of the mixture with a same set of interaction parameters. The results obtained for the four mixtures studied in this work with both theoretical models are displayed in Figure $7 a-d$, where they are graphically compared with experimental data. Likewise, Figure $6 a-d$ shows the estimations made for the concentrations $\left(y_{1}-x_{1}\right)$ versus $x_{1}$ and for the temperatures $T$ versus $x_{1}$, with $y_{1}$ values obtained starting with a given concentration $x_{1}$. Several observations can be made about this set: the two versions of the UNIFAC model used here produce very similar estimations, although they give results different from experimental values, and these differences increase as the chain length of methanoate increases. It can be also observed that the system methyl methanoate + hexane presents the best predictions of the activity coefficients and Gibbs adimensional function, possibly due to the use of VLE data from this binary system, the only one existing in the literature at that time to determine pairs of interaction parameters $\mathrm{CH}_{2} / \mathrm{HCOO}$. Therefore, with only the odd exception, there are important discrepancies in the estimations of azeotropic points as can be observed in Table 7. However, estimation of the enthalpies with Gmehling's et al. version ${ }^{16}$ is not very deficient, with mean differences compared to experimental values of around $10 \%$, although the interaction parameters are inadequate. Figure $8 \mathrm{a}-\mathrm{d}$ shows differences between experimental values and values calculated with the model and the curve, corresponding to a difference of $10 \%$, for comparative purposes. In summary, none of the UNIFAC versions can currently be recommended to represent thermodynamic properties of systems that are characterized by the $\mathrm{CH}_{2} /$ $\mathrm{HCOO}$ interaction. In future works, with a wider database, we will try to improve the model.

\section{Literature Cited}

(1) Galvan, S.; Ortega, J.; Susial, P.; Peña, J. A. Isobaric vapor-liquid equilibria for propyl methanoate $+n$-alkanes $(\mathrm{C} 7, \mathrm{C} 8, \mathrm{C} 9)$ or n-alkanols (C2, C3, C4). J. Chem. Eng. Jpn. 1994, 27, 529-534.

(2) Ortega, J.; Espiau, F.; Postigo, M. Isobaric VLE and excess quantities for binary mixtures of an ethyl ester + tert-butyl alcohol and a new approach to VLE data processing. J. Chem. Eng. Data 2003, 48, 916924.

(3) Ortega, J.; Espiau, F.; Dieppa, R. Measurement and correlation of isobaric vapor-liquid equilibrium data and excess properties of ethyl methanoate with alkanes (hexane to decane). Fluid Phase Equilib. 2004, 215, 175-186.

(4) Ortega, J.; Espiau, J.; Tojo, J.; Canosa, J.; Rodríguez, A. Isobaric VLE and excess properties for the binary systems of methyl esters + heptane. J. Chem. Eng. Data 2003, 48, 1183-1190.
(5) Ortega, J.; Espiau, F.; Postigo, M. Excess properties and isobaric VLE for binary mixtures of methyl esters + tert-butanol. J. Chem. Eng. Data 2004, 49, 1602-1612.

(6) Ortega, J.; Espiau, F.; Postigo, M. Vapor-liquid equilibria at 101.32 $\mathrm{kPa}$ and excess properties of binary mixtures of butyl esters + tertbutyl alcohol. J. Chem. Eng. Data 2005, 50, 444-455.

(7) Ortega, J.; Espiau, F.; Sabater, G.; Postigo, M. Correlation and prediction of excess quantities and VLE of alkyl esters + tert-butyl alcohol: Experimental data for propyl esters + tert-butyl alcohol. $J$. Chem. Eng. Data 2006, 51, 730-742.

(8) Ogorodnikov, S. K.; Kogan, V. B.; Nemtsov, M. S. Liquid-vapor equilibrium in systems formed by hydrocarbons and methyl formate. Zh. Prikl. Khim. 1961, 34, 581-585.

(9) Ortega, J.; Placido, J.; Toledo, F.; Vidal, M.; Siimer, E.; Legido, J. L. Behaviour of binary mixtures of an alkyl methanoate + an $n$-alkane. New experimental values and interpretation using UNIFAC model. Phys. Chem. Chem. Phys. 1999, 1, 2967-2974.

(10) Matos, J. S.; Ortega, J.; Tardajos, G.; Garcia, M. V.; Legido, J. L. Análisis of volumes of mixing for propyl and butyl formate with $n$-alkanes in terms of the Nitta model. J. Solution Chem. 1990, 19 (11), 1063-1071.

(11) Ortega, J. Excess enthalpies of alkyl formates $+(n$-alkanes or 1-chloroalkanes). Experimental data and their analysis in terms of the UNIFAC model. Ber. Bunsen-Ges. Phys. Chem. 1989, 93, 730735.

(12) Ortega, J.; Legido, J. L.; Fernández, J.; López, M.; Pias, L.; Paz, M. I. Analysis of excess enthalpies of ethyl formate $+n$-alkane or 1-alkanol with two group contribution models. Fluid Phase Equilib. 1990, 56, 219-234.

(13) Ferloni, P. Liquid-liquid equilibrium. Methyl methanoate (methyl formate)-hexane system. Intl. DATA Ser., Sel. Data Mixtures Ser. A 1975, 1,80 .

(14) Nagata, I. Excess enthalpy. Ethyl methanaote-hexane system. Intl. DATA Ser., Sel. Data Mixtures Ser. A 1984, 1, 58.

(15) Hansen, H. K.; Rasmussen, P.; Fredenslund, Aa.; Schiller, M.; Gmehling, J. Vapor-liquid equilibria by UNIFAC group contribution. 5. Revision and extension. Ind. Eng. Chem. Res. 1991, 30, 2355-2358.

(16) Gmehling, J.; Li, J.; Schiller, M. A modified UNIFAC model. 2 Present parameter matrix and results for different thermodynamic properties. Ind. Eng. Chem. Res. 1993, 32, 178-193.

(17) Riddick, J. A; Bunger, W. B.; Sakano, T. K. Organic Solvents: Physical Properties and Methods of Purification, 4th ed.;Techniques of Chemistry; Wiley-Interscience: New York, 1986; Vol. II.

(18) Lide, D. R.; Kehiaian, H. V. CRC Handbook of Thermophysical and Thermochemical Data; CRC Press: Boca Raton, FL, 1994.

(19) TRC. Thermodynamic Tables Non-Hydrocarbons \& Hydrocarbons; Thermodynamic Research Center, Texas A\&M University System: College Station, TX, 1965.

(20) Van Ness, H. C.; Abbott, M. M. Excess enthalpy for binary mixture ethanol + nonane. Intl. DATA Ser., Sel. Data Mixture Ser. A 1976, 1, 14.

(21) Bondi, A. Physical Properties of Molecular Crystals, Liquids and Glasses; Wiley: New York, 1968.

(22) Ortega, J.; Espiau, F. A new correlation method for VLE and excess enthalpies for nonideal solutions using a genetic algorithm. Application to ethanol + alkane mixtures. Ind. Eng. Chem. Res. 2003, 42, 49784992.

(23) Tsonopoulos, C. Second virial coefficients of water pollutions. AIChE J. 1978, 24, 1112-1115.

(24) Spencer, C. F. Danner, R. P. Improved equation for prediction of saturated liquid density. J. Chem. Eng. Data 1972, 17, 236-241.

(25) Reid, R. C.; Prausnitz, J. M.; Poling, B. E. The Properties of Gases and Liquids, 4th ed.; McGraw Hill: New York, 1988.

(26) Fredenslund, Aa.; Gmehling, J.; Rasmussen, P. Vapor-Liquid Equilibria Using UNIFAC. A Group Contribution Method; Elsevier: Amsterdam, 1977.

(27) Gmehling, J.; Menke, J.; Krafczyk, J.; Fischer, K. Azeotropic Data; VCH: Weinheim, 1994.

(28) Horsley, L.H. Azeotropic Data-III; American Chemical Society: Washington, DC, 1973.

(29) Gmehling, J; Onken, U.; Grenzheuser, P. Vapor-Liquid Equilibrium Data Collection; Dechema: Frankfurt/Main, 1982; Vol. I, Part 5, p 329.

Received for review August 10, 2006. Accepted October 31, 2006. The authors thank the Ministerio Educacion y Ciencia of Spain for funding this work via Project PPQ2003-04404.

JE060355J 